\title{
VERTEBRATES
}

default $p$-values

Fig. S1
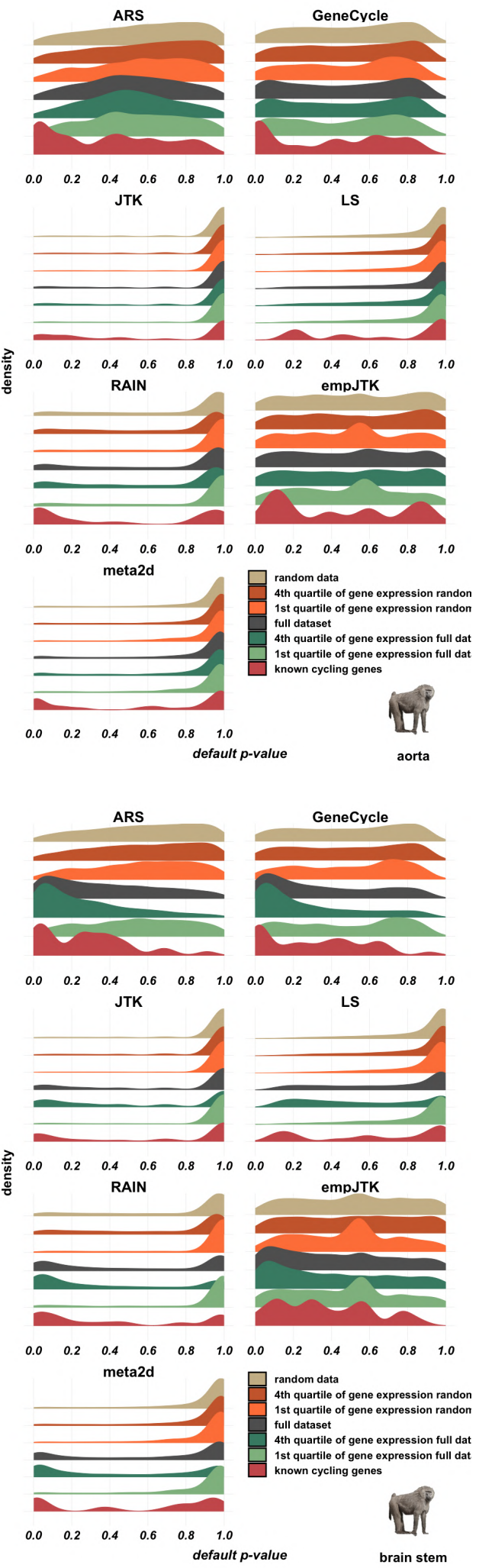

Fig. S2 


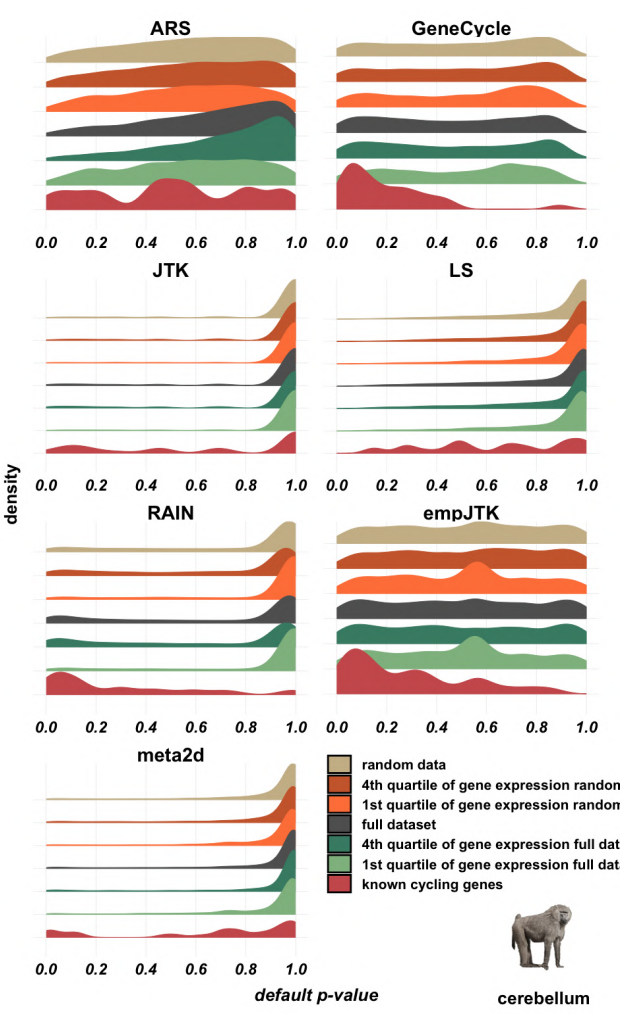

Fig. S3

Fig. S4

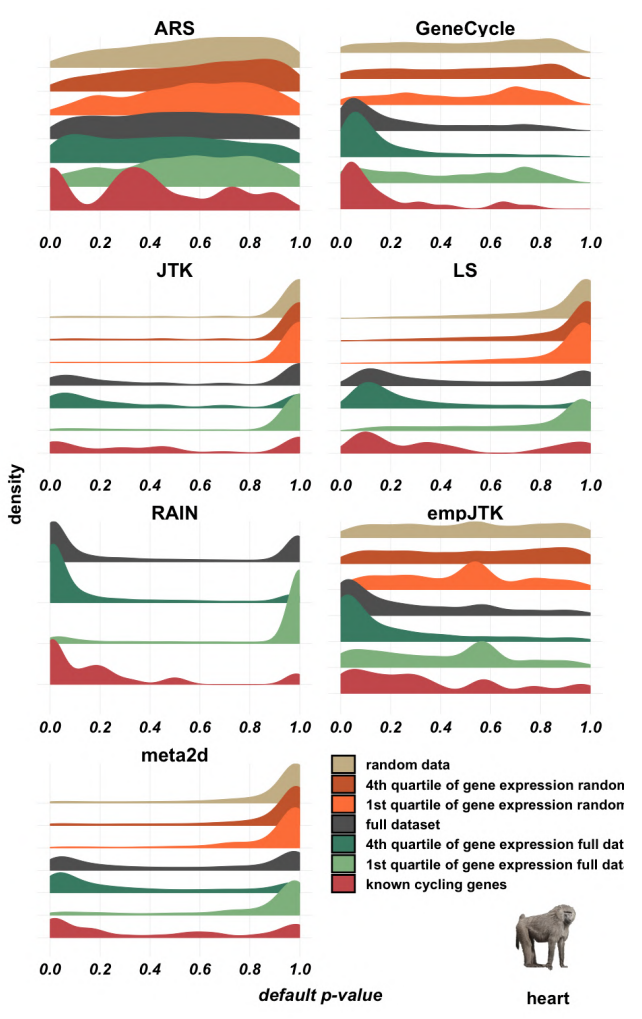




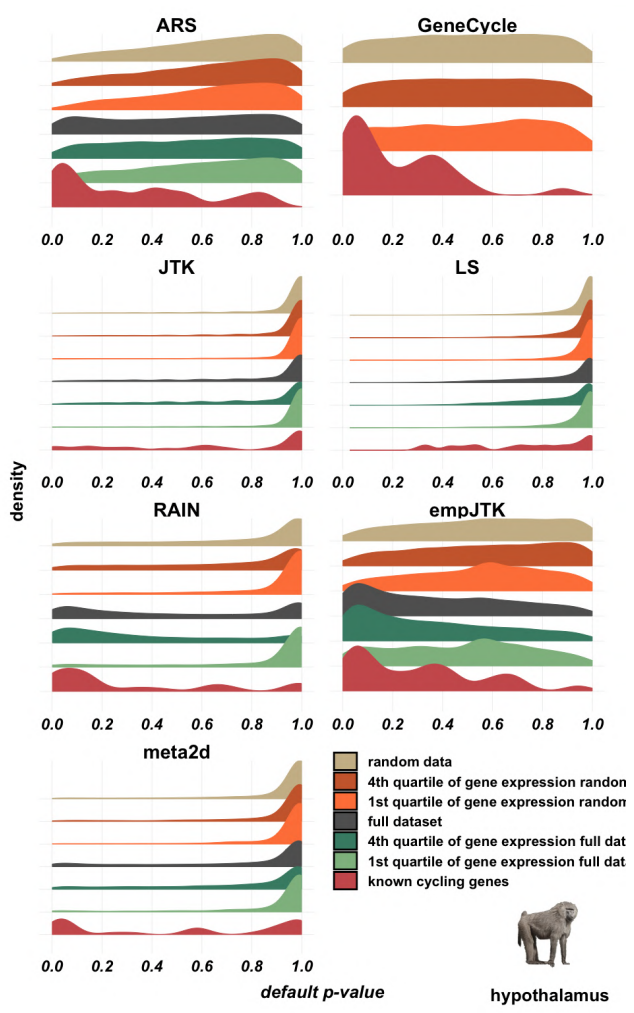

Fig. S5

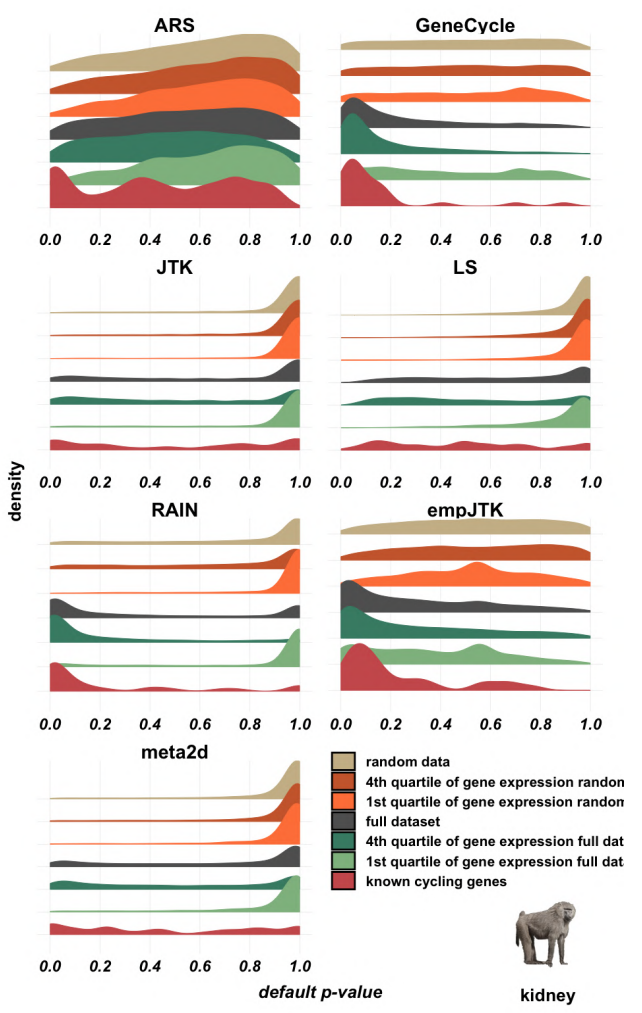

Fig. 56 


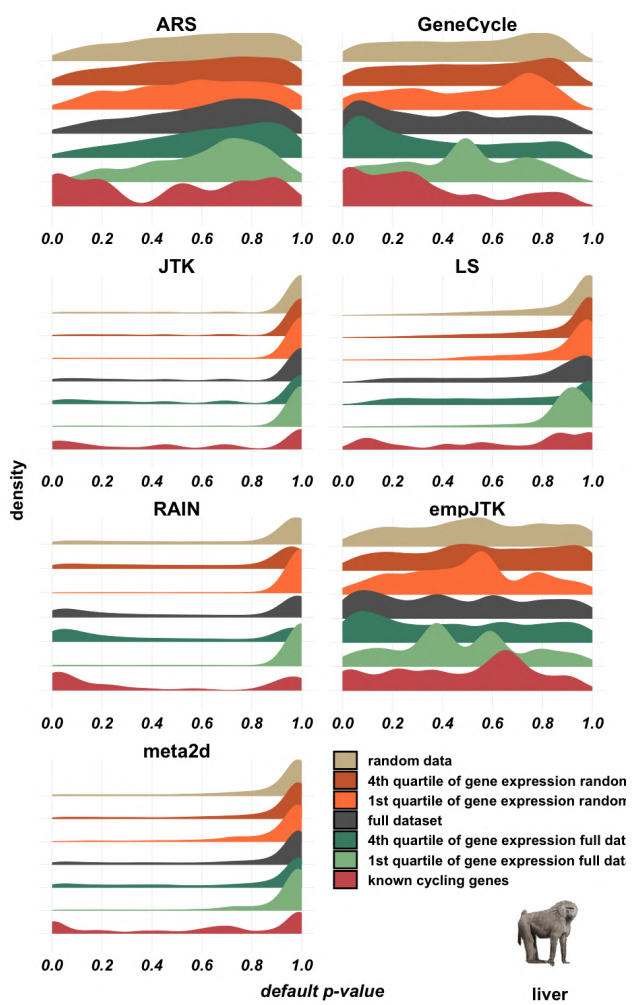

Fig. 57

Fig. S8

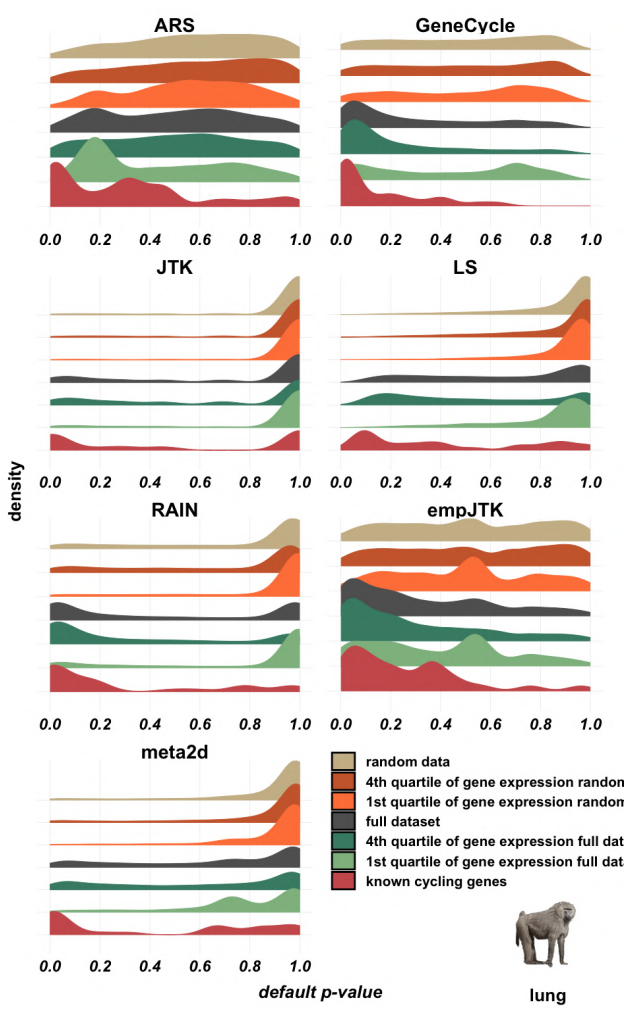




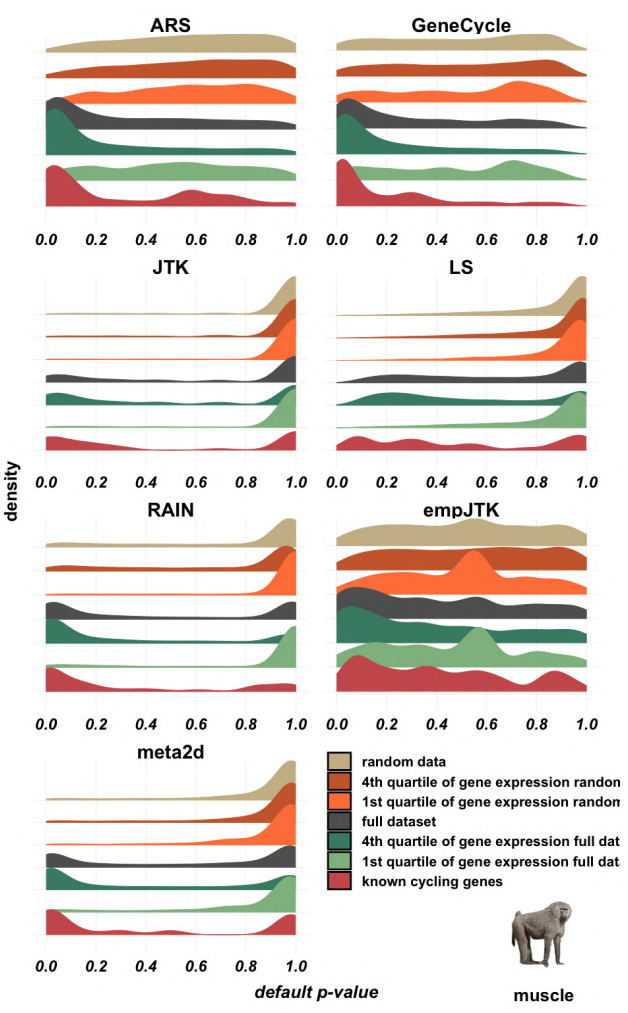

Fig. 59

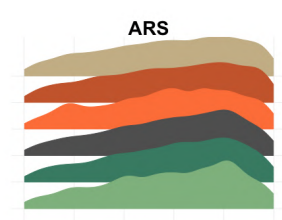

GeneCycle
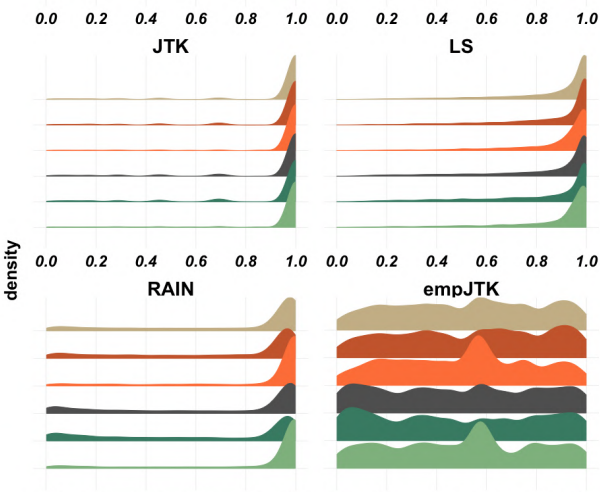

$\begin{array}{llllllllllll}0.0 & 0.2 & 0.4 & 0.6 & 0.8 & 1.0 & 0.0 & 0.2 & 0.4 & 0.6 & 0.8 & 1.0\end{array}$

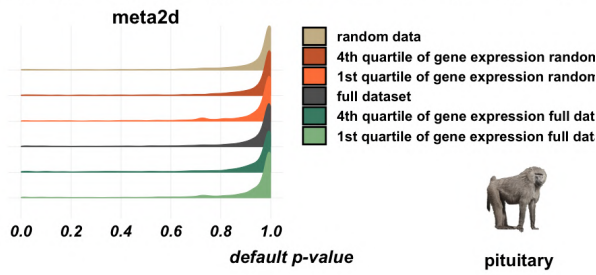

Fig. $\mathbf{S 1 0}$ 


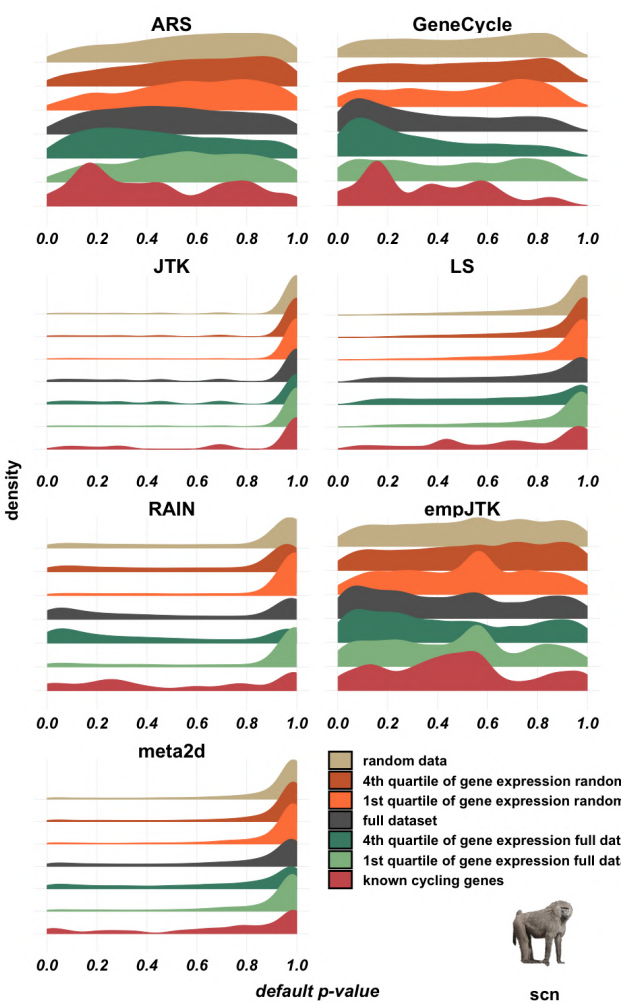

Fig. $\mathbf{S 1 1}$

Fig. $\mathbf{S 1 2}$

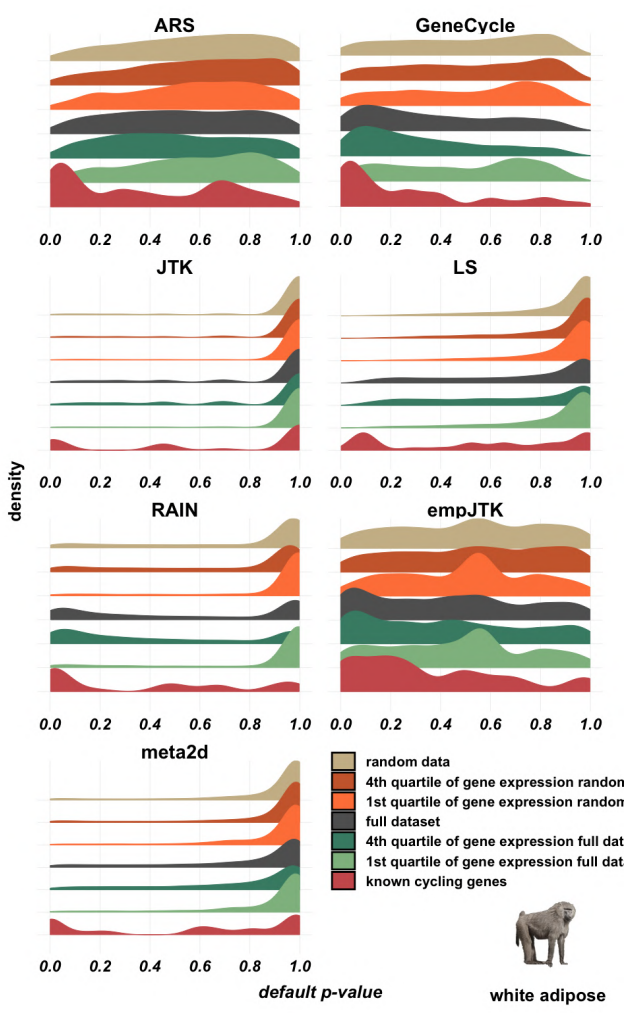




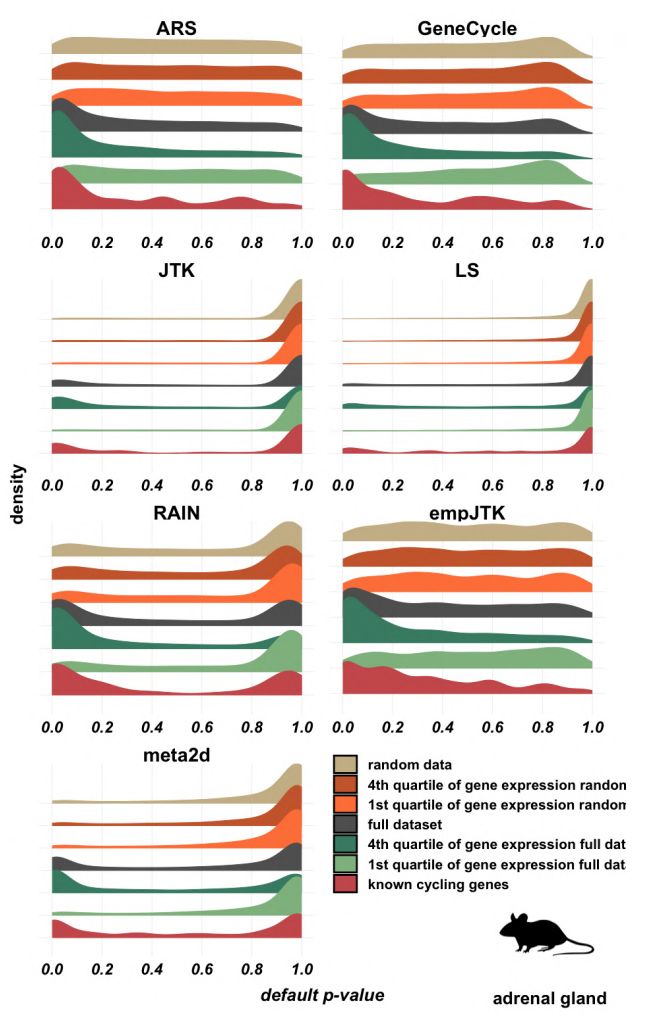

Fig. S13

Fig. $\mathbf{S 1 4}$

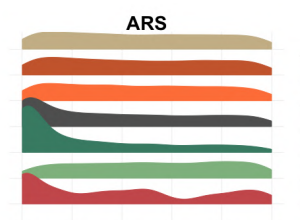

GeneCycle
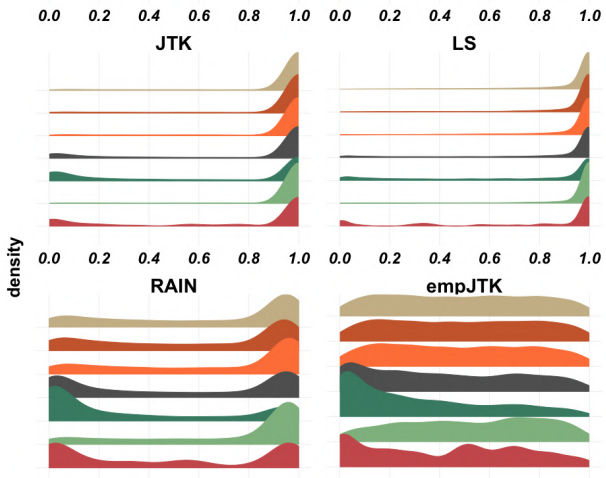

$\begin{array}{llllllllllll}0.0 & 0.2 & 0.4 & 0.6 & 0.8 & 1.0 & 0.0 & 0.2 & 0.4 & 0.6 & 0.8 & 1.0\end{array}$ meta2d

random data

4th quartile of gene expression rando

st quartile of gene expression rando

full dataset

expression full dat

ist quartile of gene expression full dat

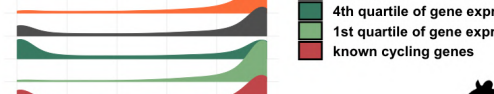

$\begin{array}{llllll}0.0 & 0.2 & 0.4 & 0.6 & 0.8 & 1.0\end{array}$

default p-value

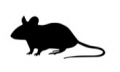

aorta 

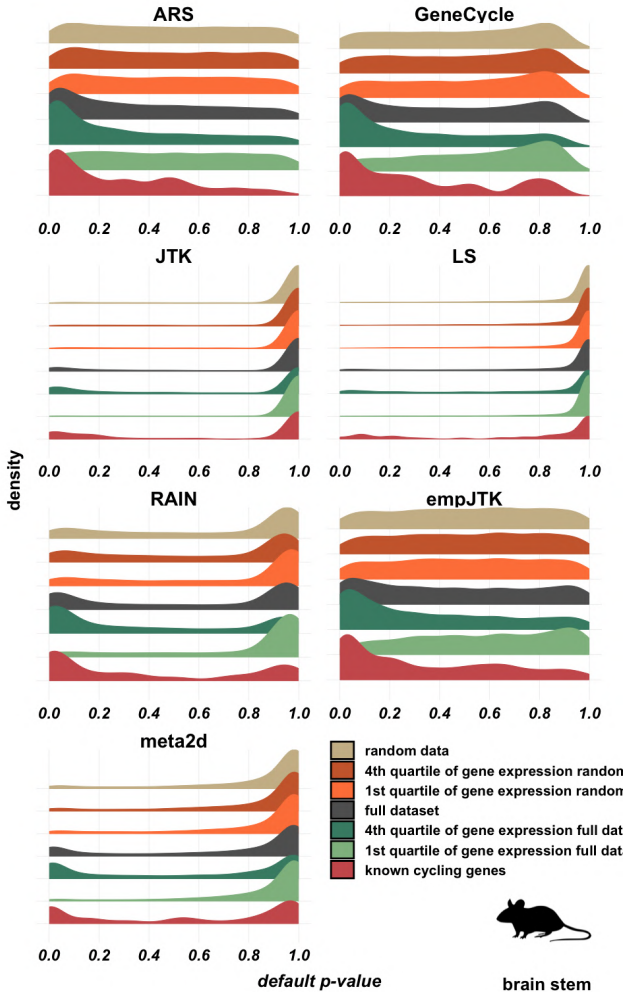

Fig. S15

Fig. $\mathbf{S 1 6}$

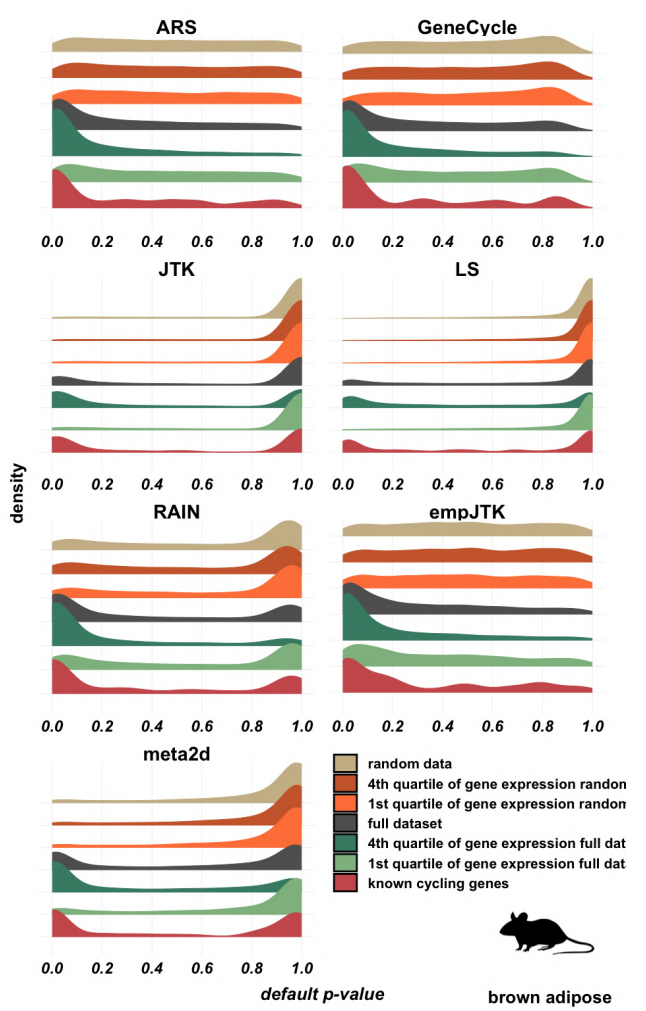




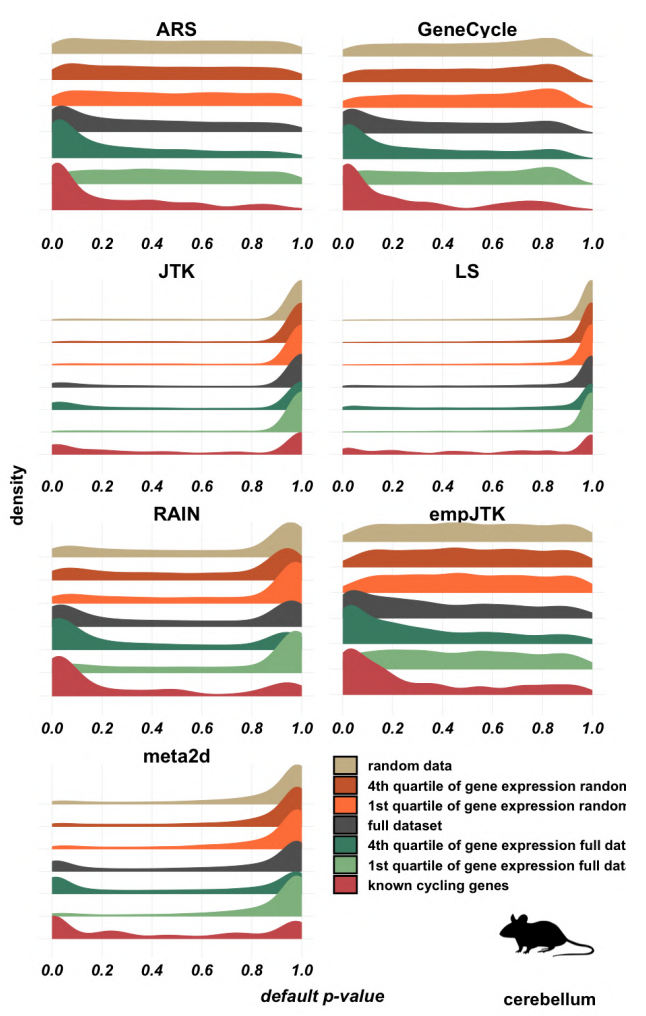

Fig. S17

Fig. $\mathbf{S 1 8}$

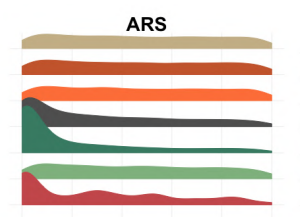

GeneCycle

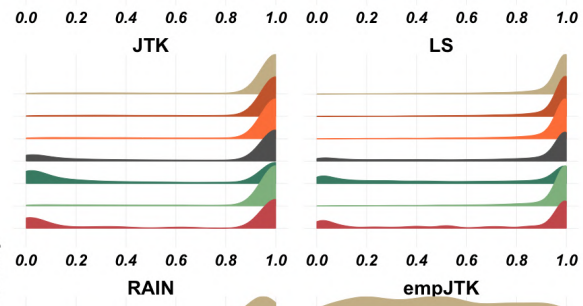

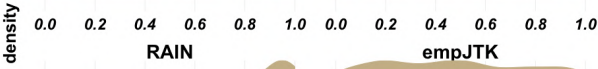

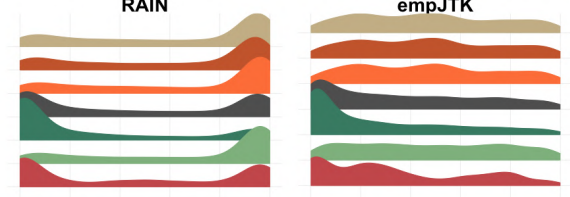

$\begin{array}{llllllllllll}0.0 & 0.2 & 0.4 & 0.6 & 0.8 & 1.0 & 0.0 & 0.2 & 0.4 & 0.6 & 0.8 & 1.0\end{array}$

meta2d

random data

4th quartile of gene expression randon

1st quartile of gene expression rando

full dataset

ne expression full dat

st quartile of gene expression full dat

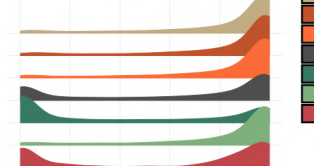

$\begin{array}{llllll}0.0 & 0.2 & 0.4 & 0.6 & 0.8 & 1.0\end{array}$

default p-value

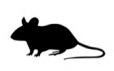

heart 


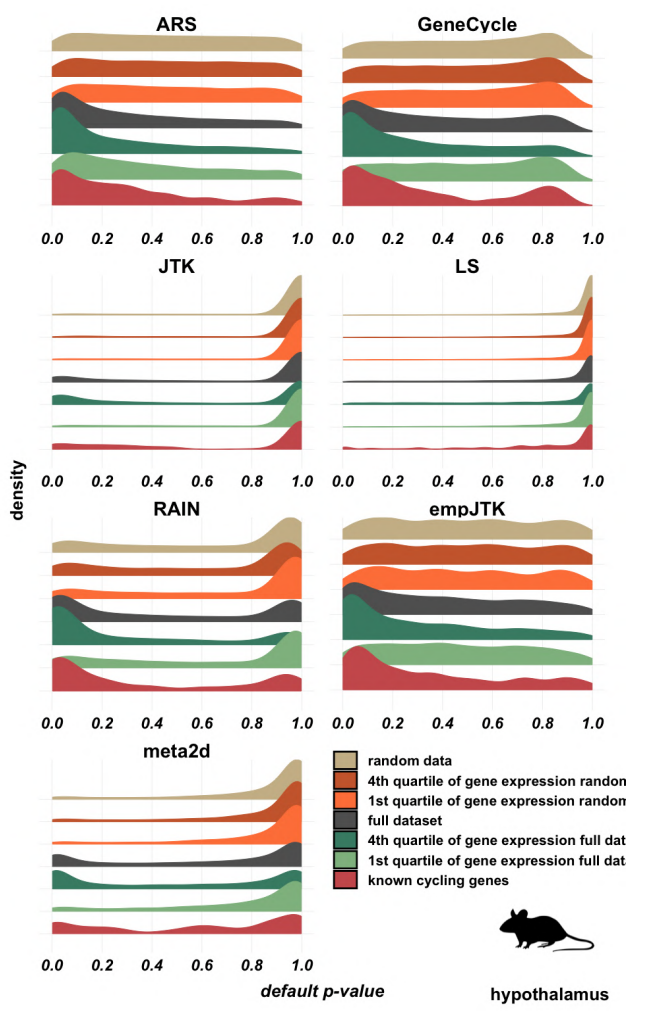

Fig. $\$ 19$

Fig. S20

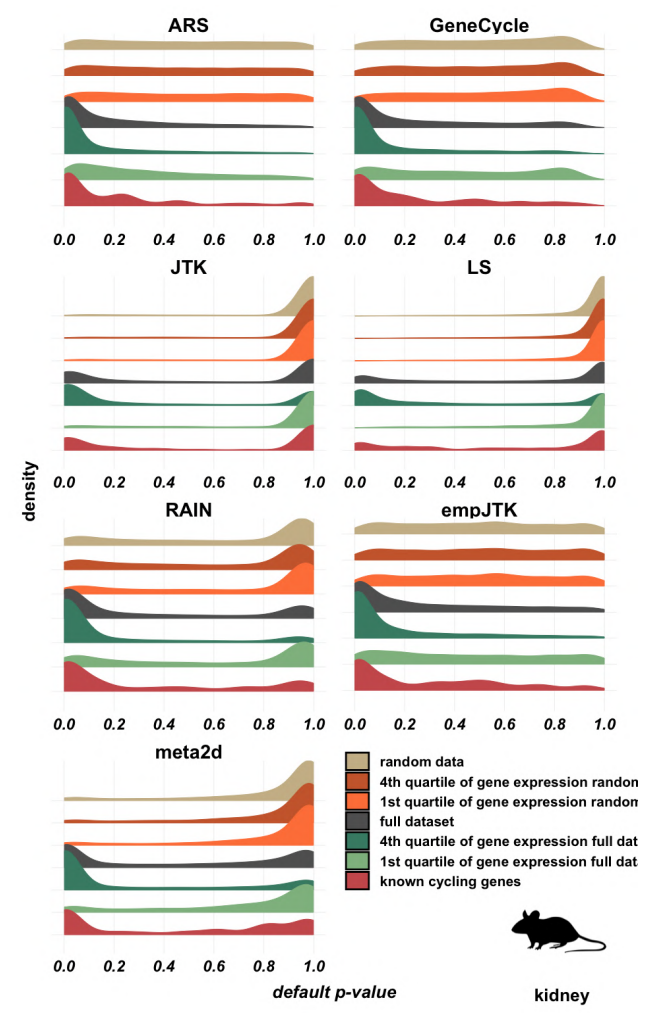




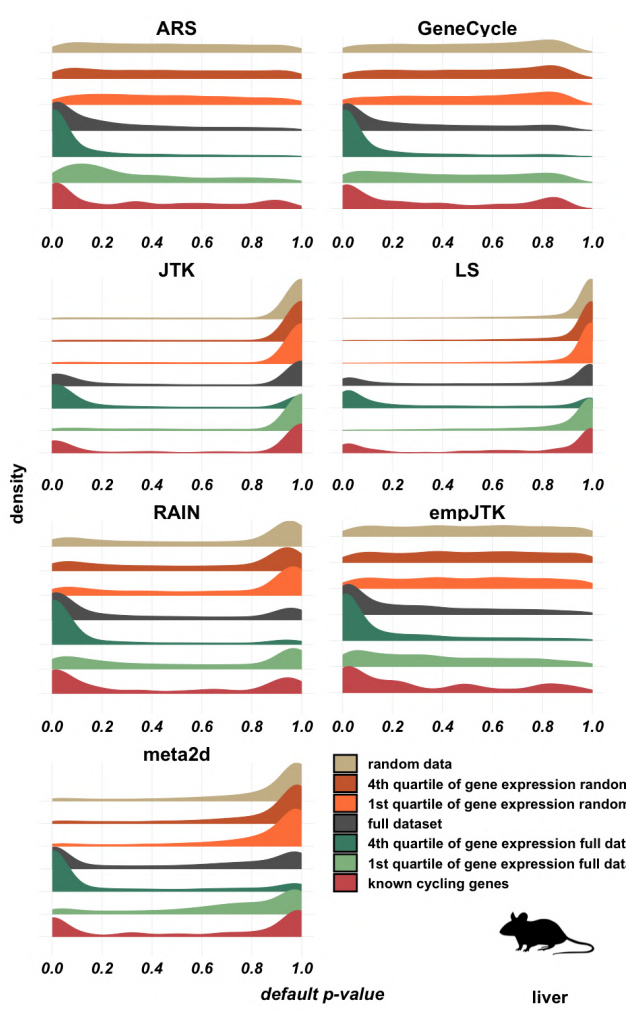

Fig. S21

Fig. S22

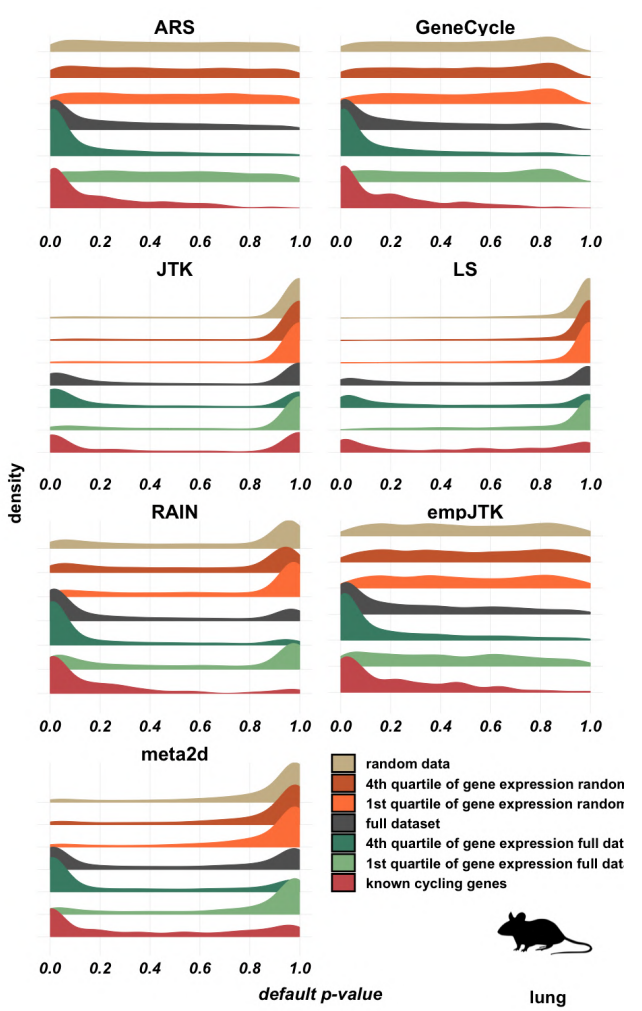




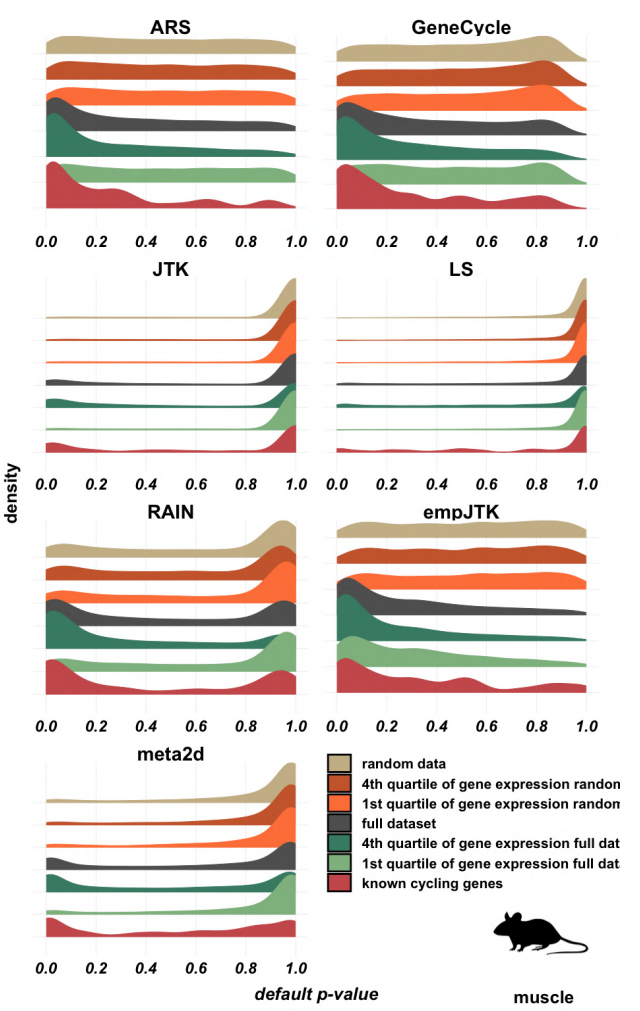

Fig. S23

Fig. S24

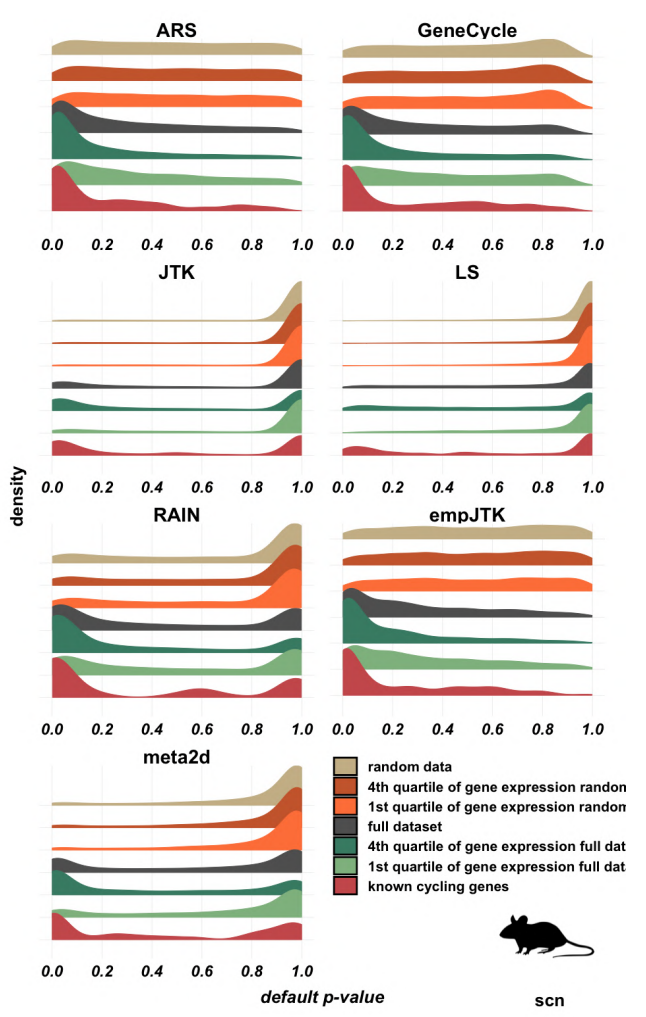




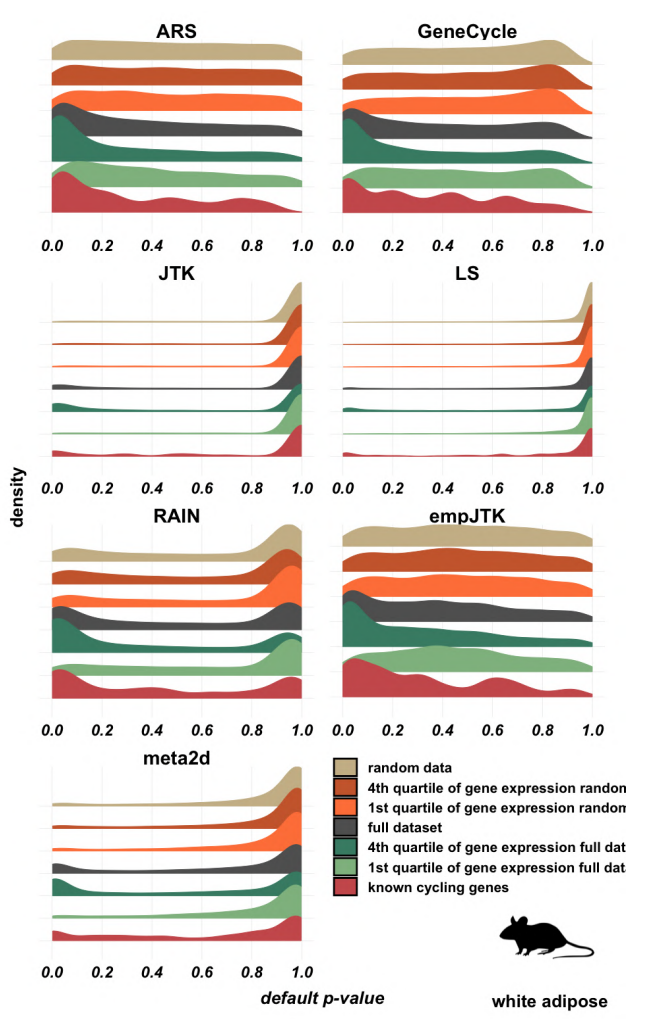

Fig. S25

Fig. S26

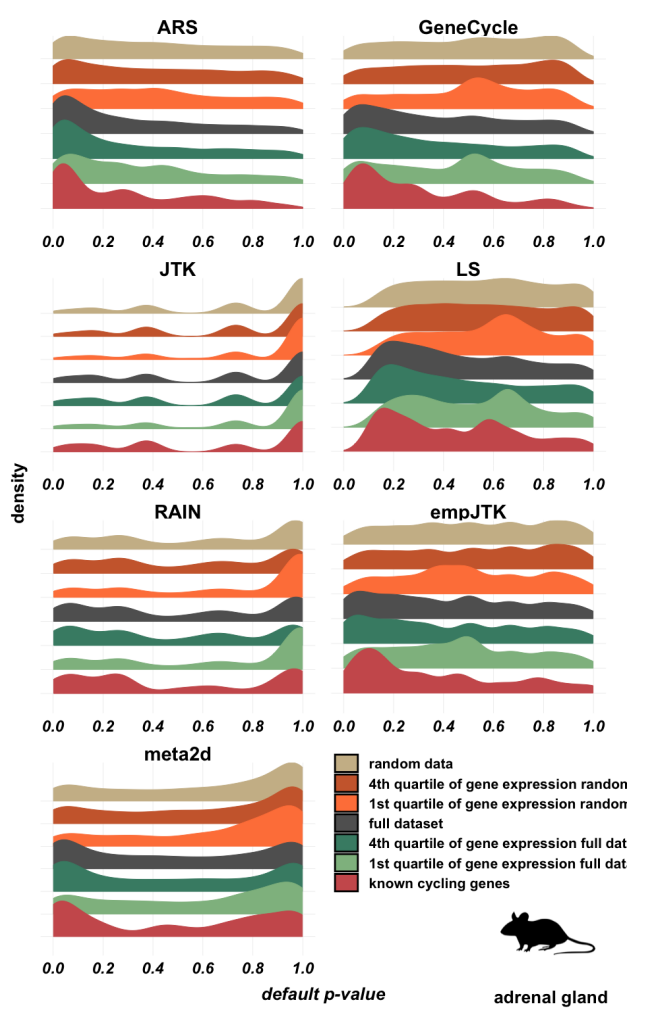




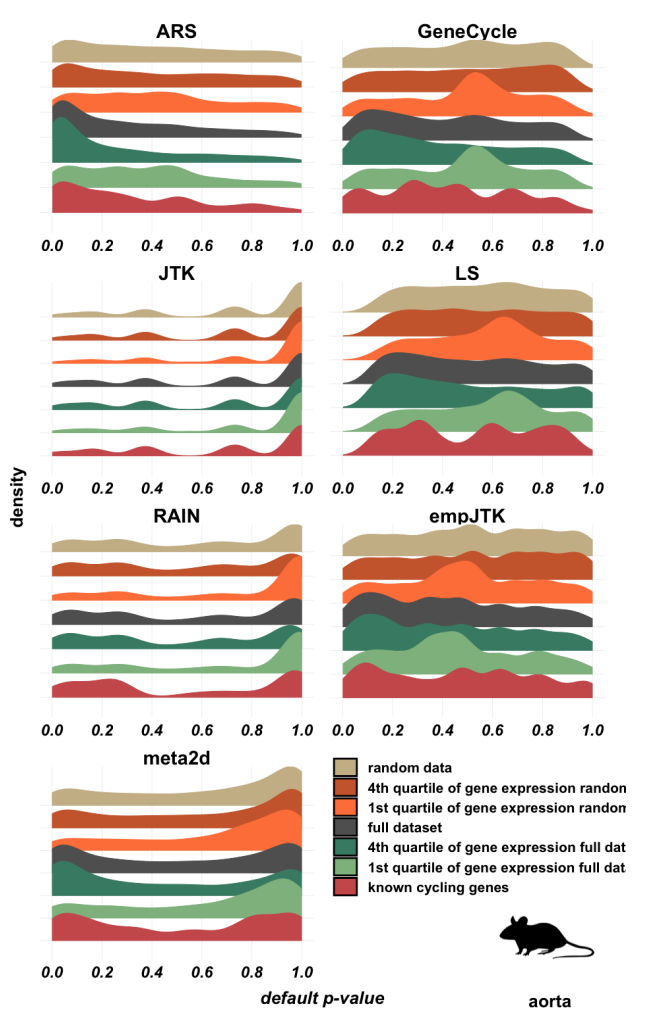

Fig. 527

Fig. S28
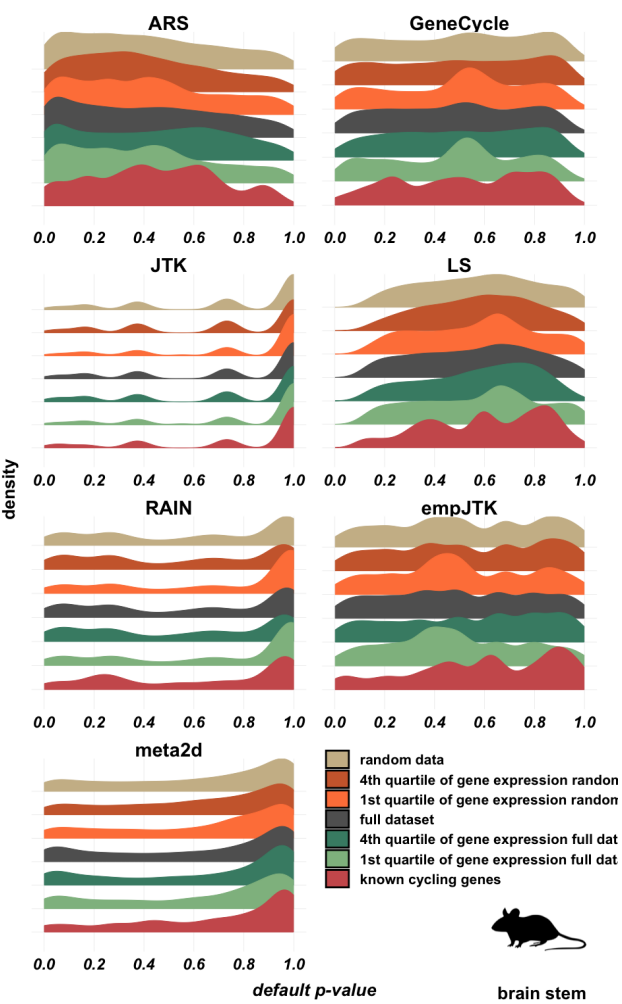
Fig. S29
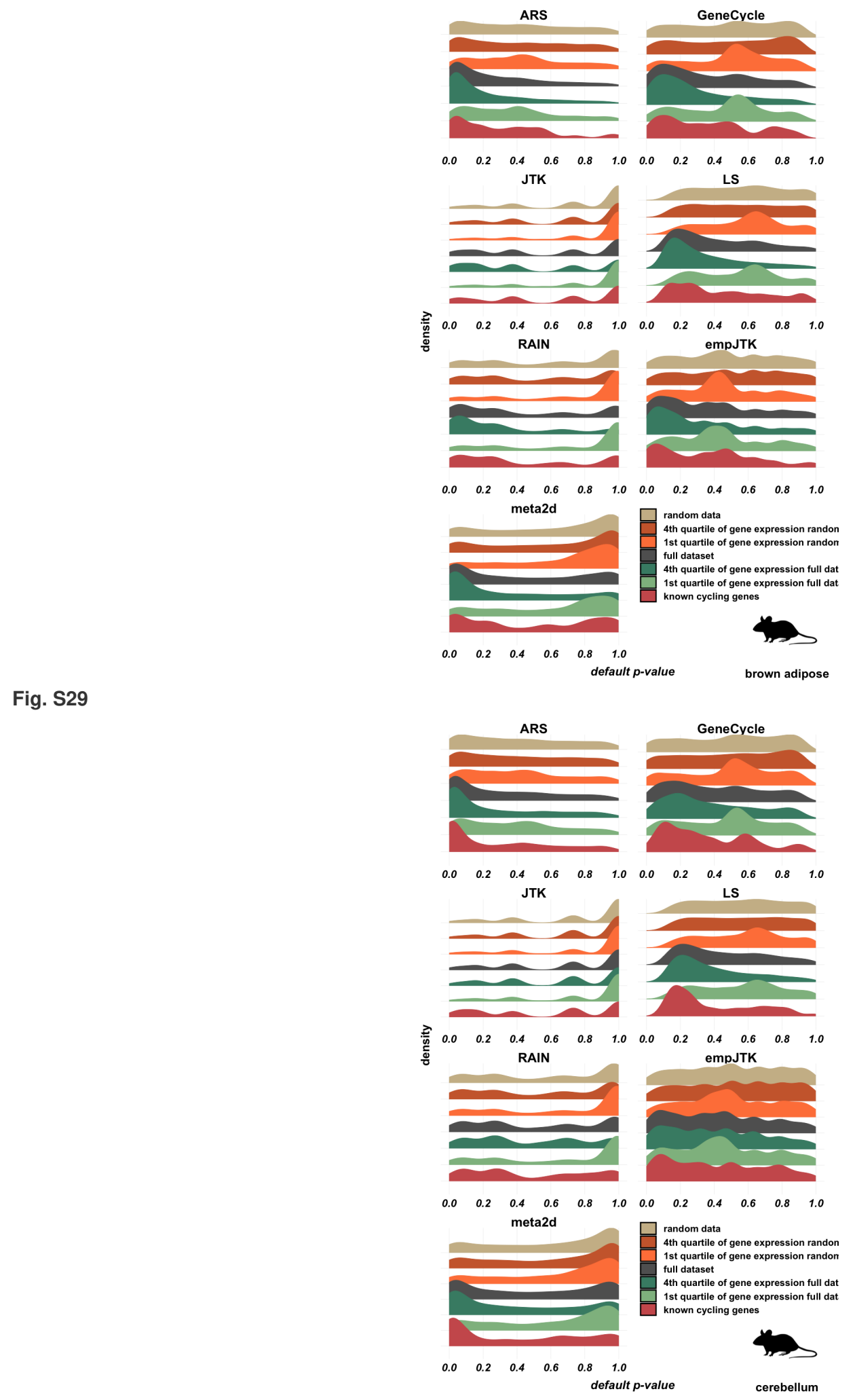

Fig. $\$ 30$ 
Fig. S31
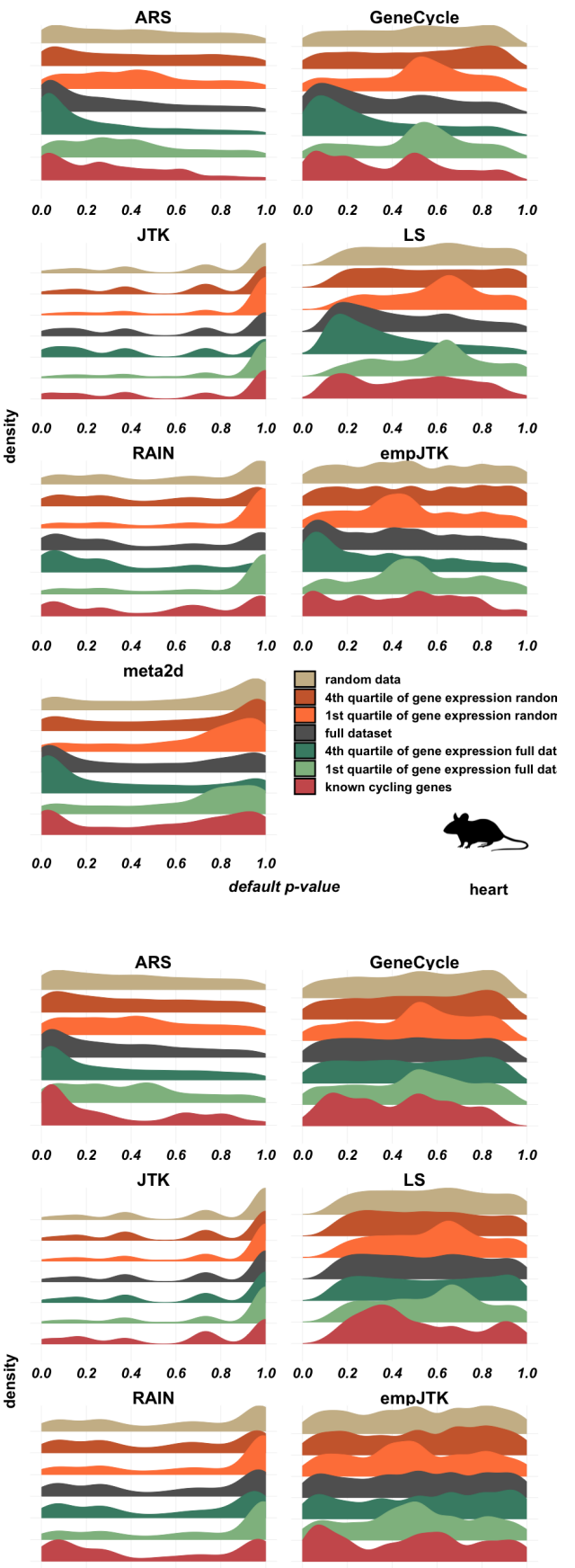

$\begin{array}{llllllllllll}0.0 & 0.2 & 0.4 & 0.6 & 0.8 & 1.0 & 0.0 & 0.2 & 0.4 & 0.6 & 0.8 & 1.0\end{array}$

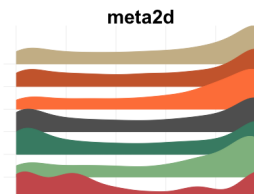

random data

4 th quartile of gene expression rando

tht quartile of gene expression rando

full datase

ne expression full da

The expression full dat

1st quartile of gene expros
known cycling genes

$\begin{array}{llllll}0.0 & 0.2 & 0.4 & 0.6 & 0.8 & 1.0\end{array}$

default p-value

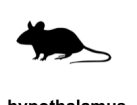

Fig. S32 
Fig. S33
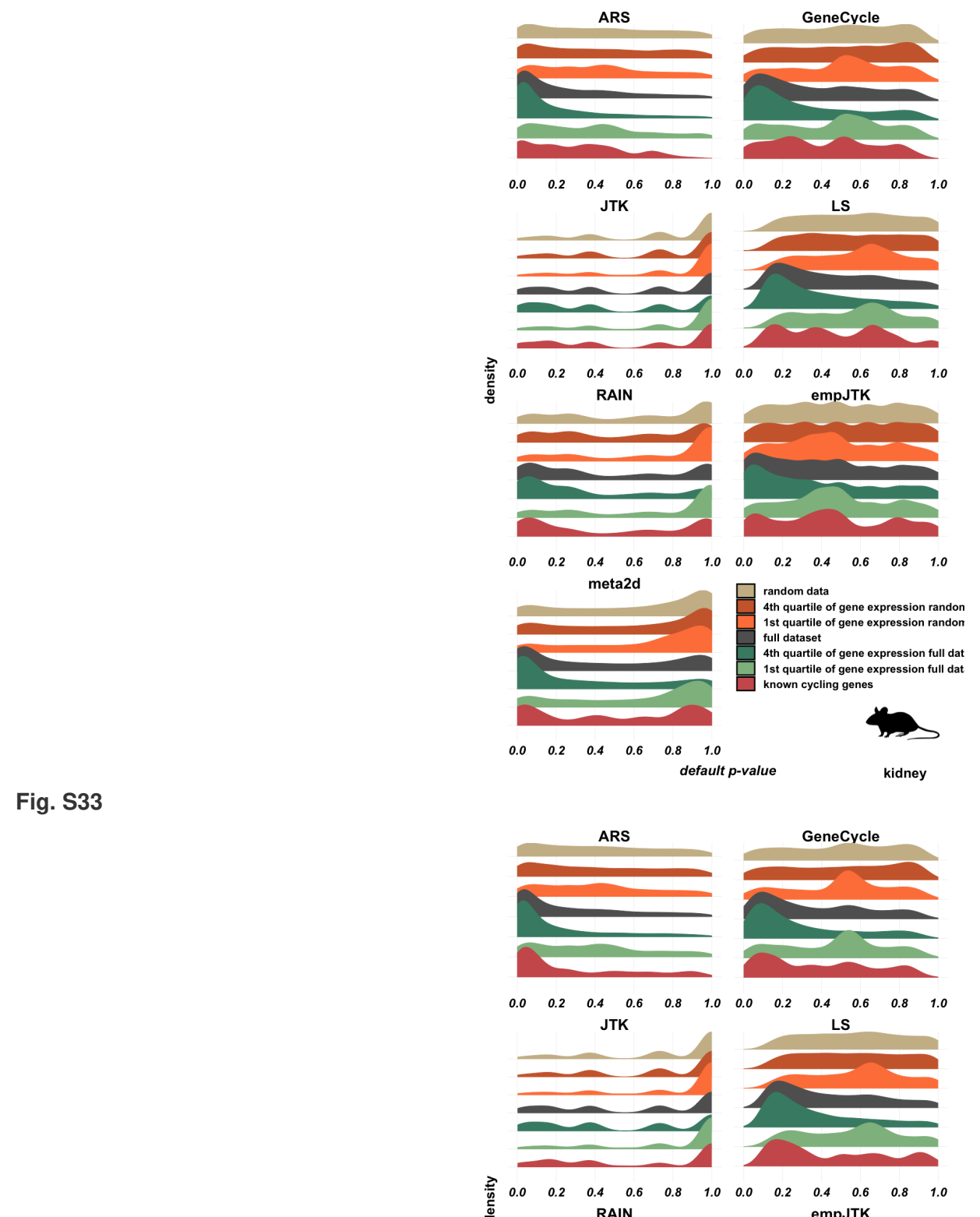

商
$\frac{0}{0}$
$\frac{0}{0}$

RAIN empJTK
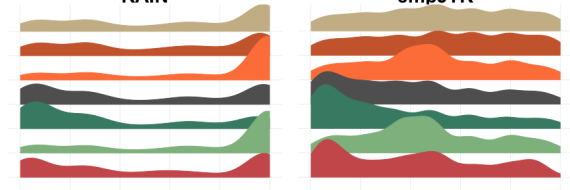

$\begin{array}{llllllllllll}0.0 & 0.2 & 0.4 & 0.6 & 0.8 & 1.0 & 0.0 & 0.2 & 0.4 & 0.6 & 0.8 & 1.0\end{array}$ meta2d

random data

4th quartile of gene expression rando

st quartile of gene expression rando

full dataset

expression full dat

ist quartile of gene expression full dat

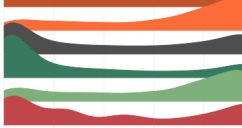

$\begin{array}{llllll}0.0 & 0.2 & 0.4 & 0.6 & 0.8 & 1.0\end{array}$

default p-value

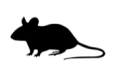

Fig. S34 


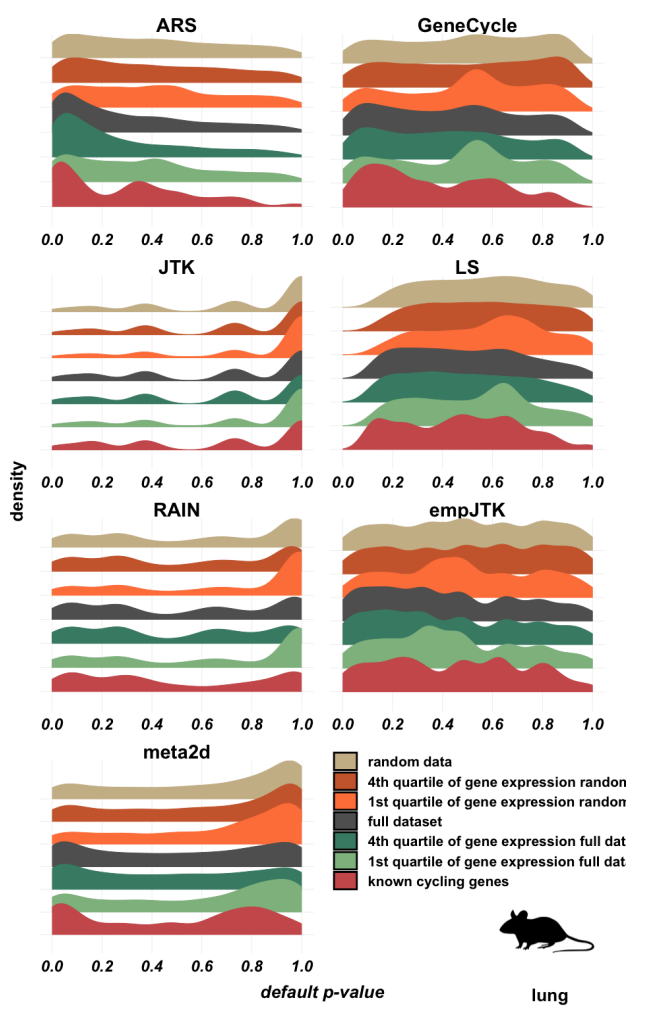

Fig. S35

Fig. S36

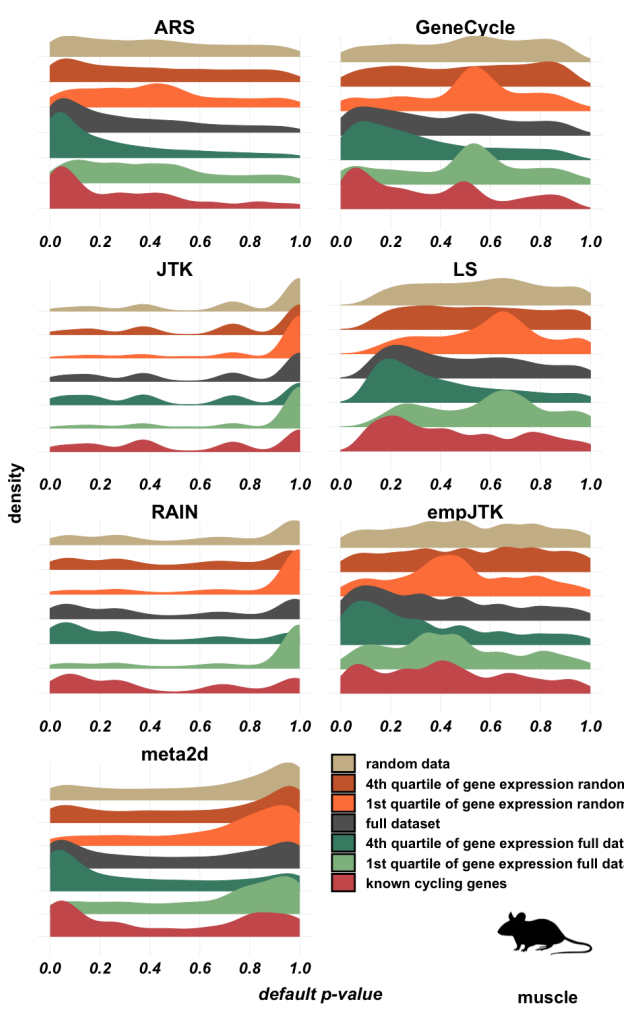



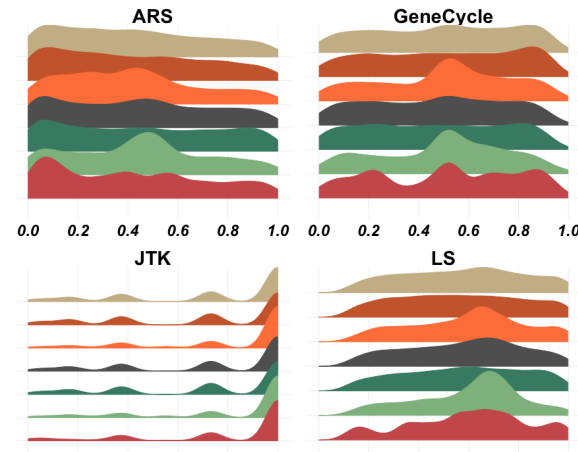

존

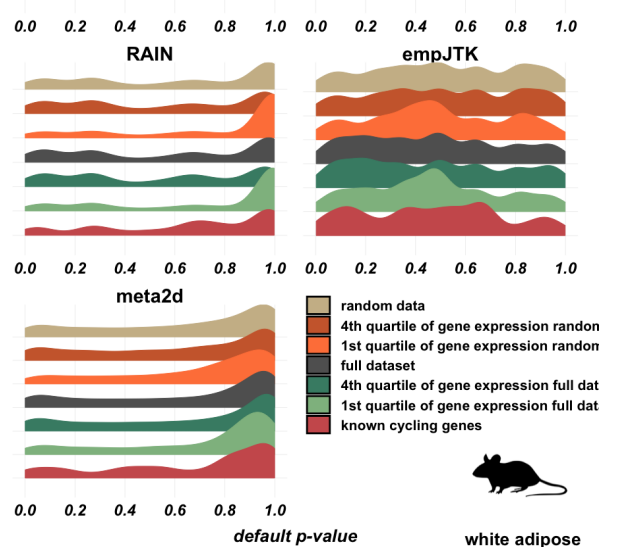

Fig. S37

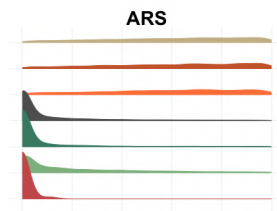

GeneCycle

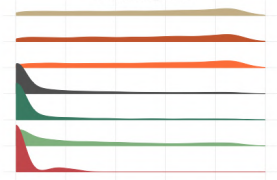

$\begin{array}{llllllllllll}0.0 & 0.2 & 0.4 & 0.6 & 0.8 & 1.0 & 0.0 & 0.2 & 0.4 & 0.6 & 0.8 & 1.0\end{array}$
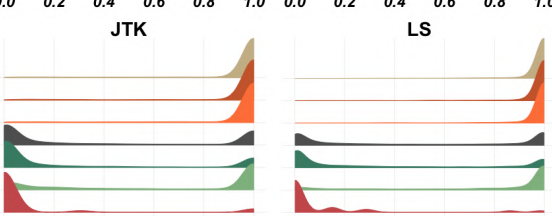

$\frac{3}{0}$
$\frac{0}{0}$
$\frac{0}{0}$
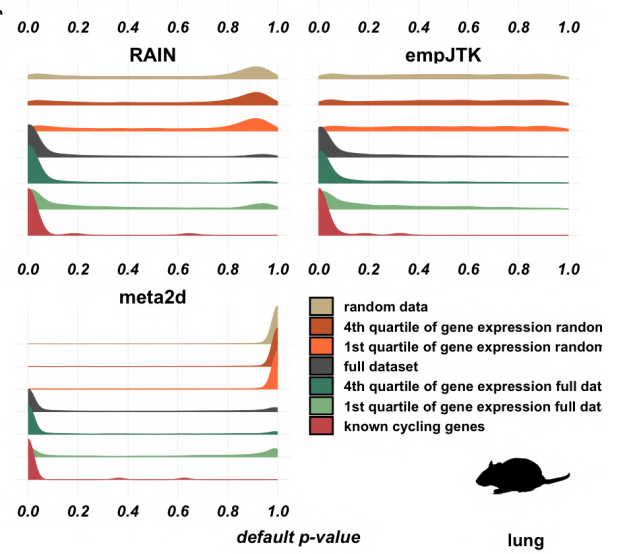

Fig. $\mathbf{S 3 8}$ 


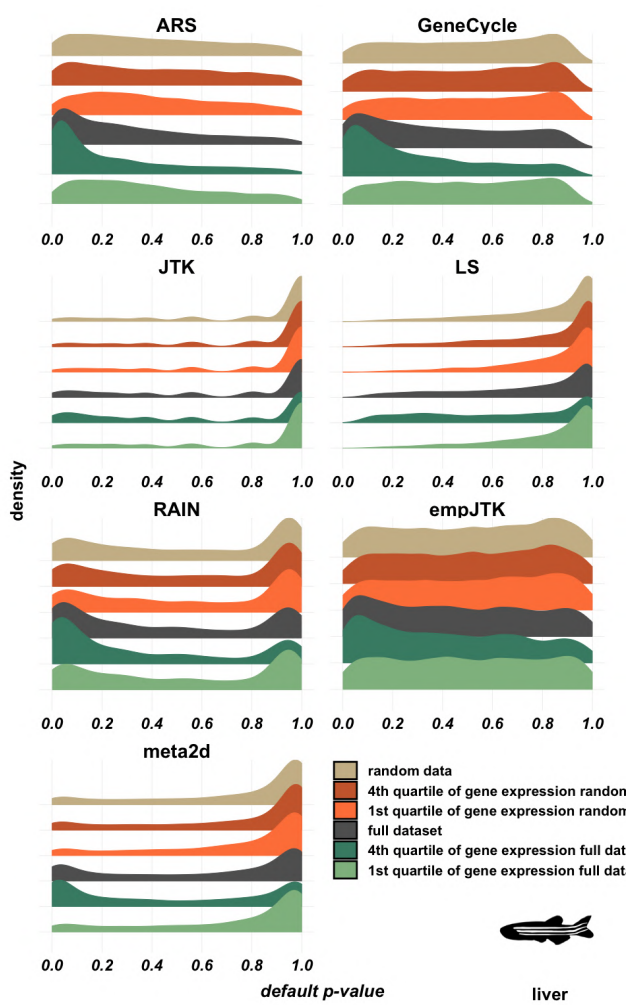

Fig. S39

\section{raw $p$-values}

Fig. $\$ 40$

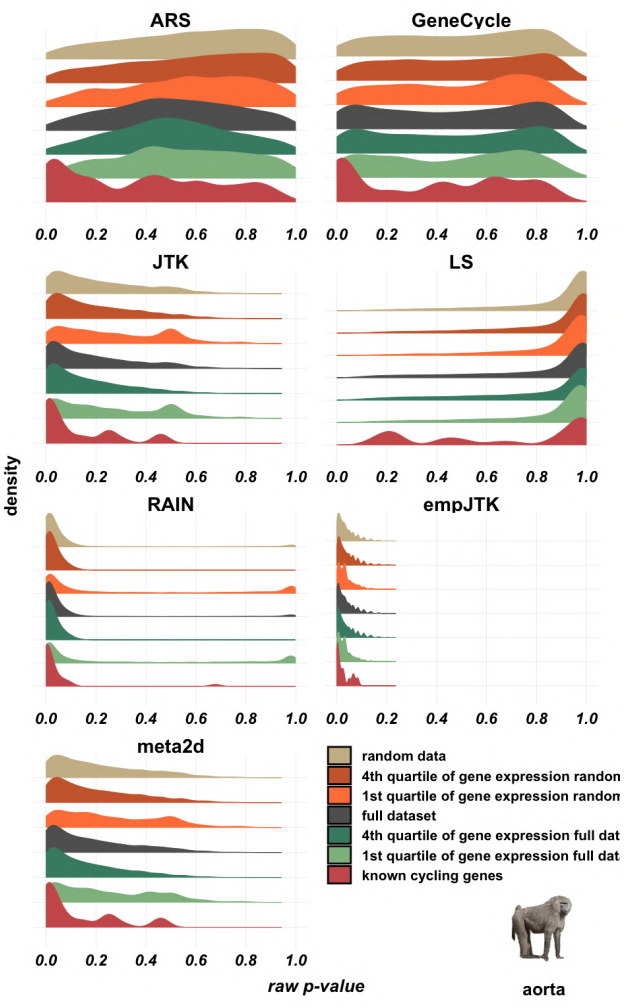




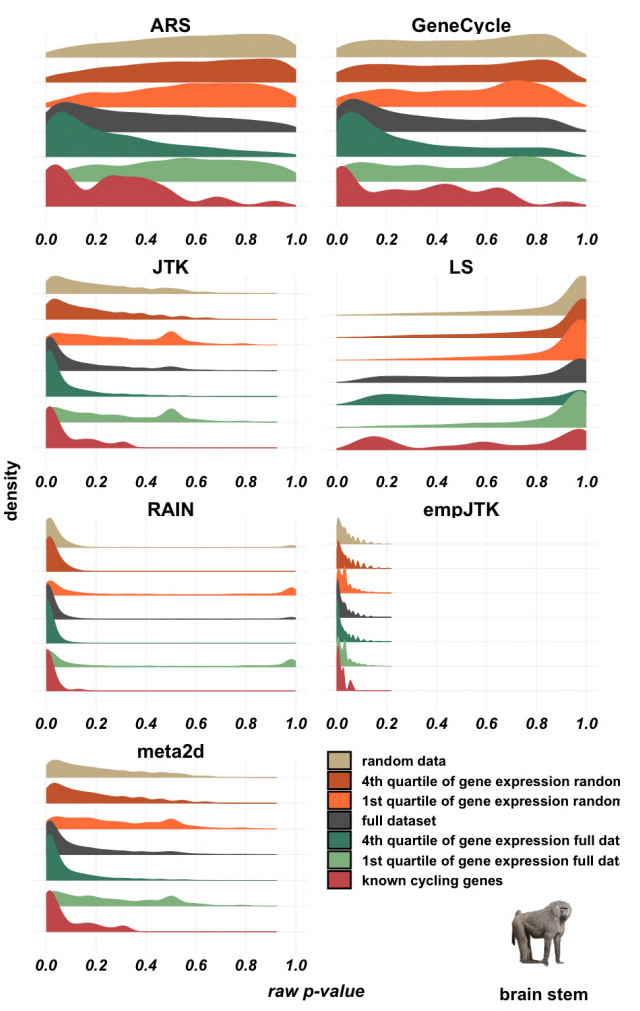

Fig. S41
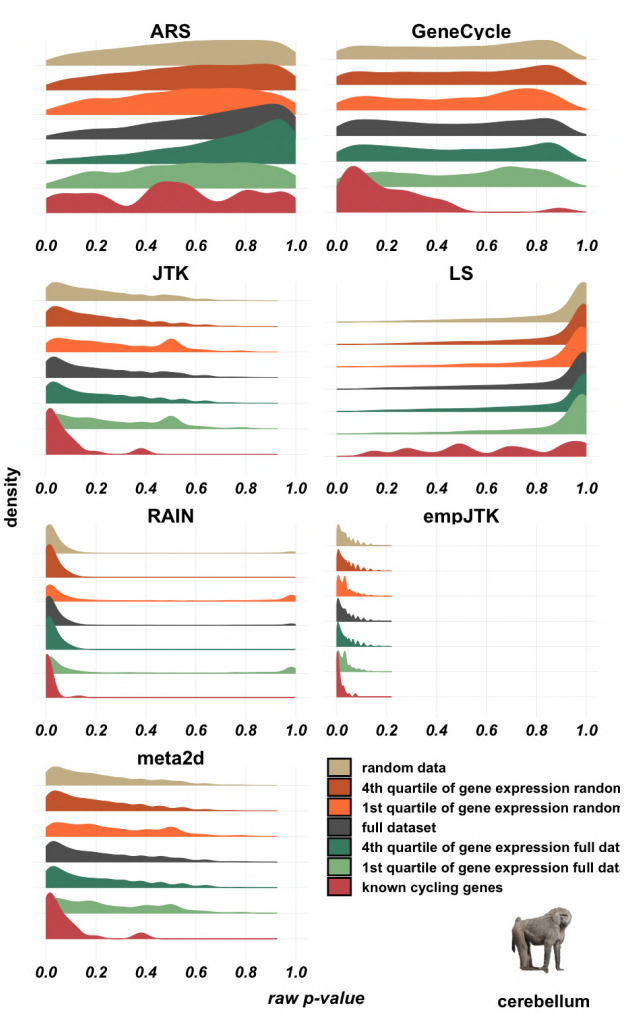

Fig. $\mathbf{S 4 2}$ 


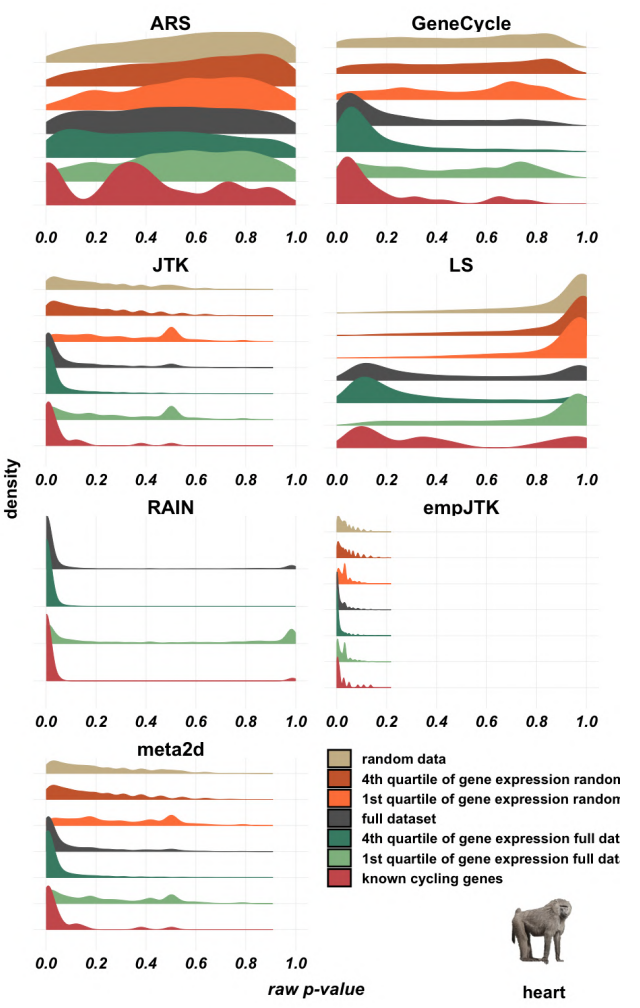

Fig. S43

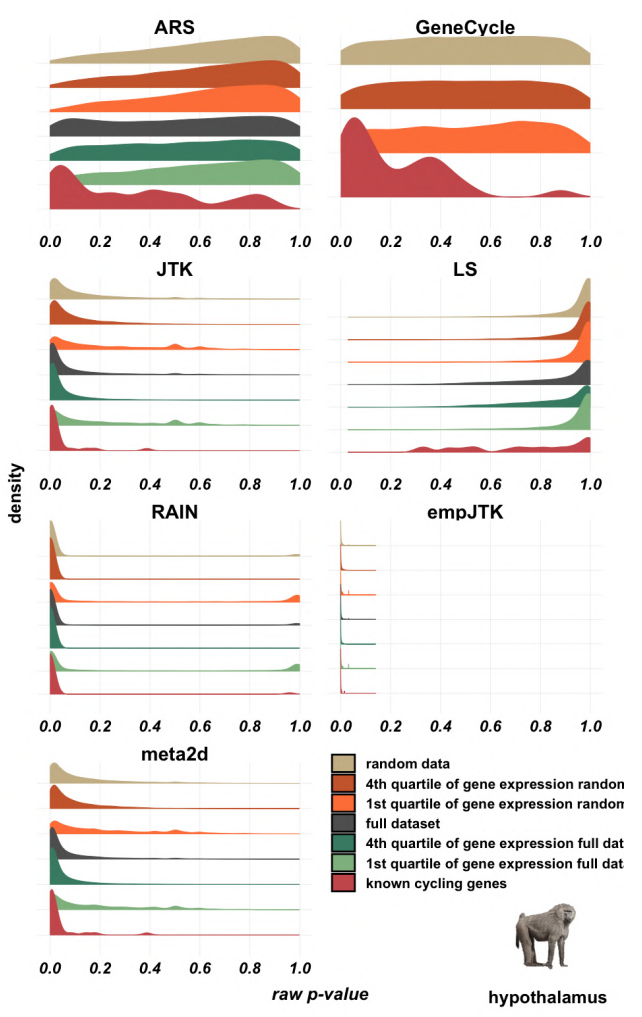

Fig. S44 


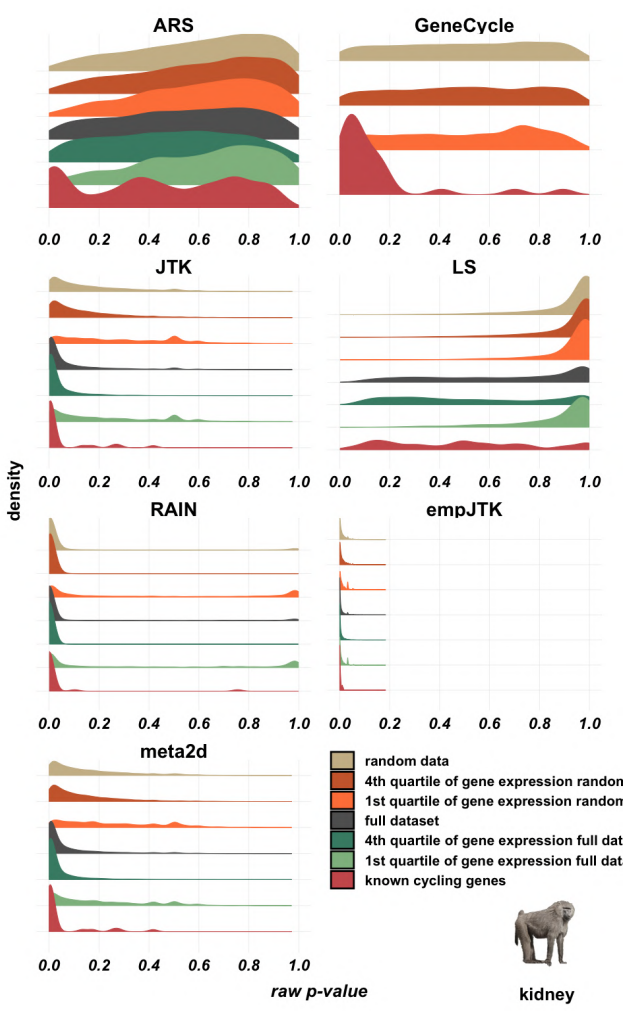

Fig. S45
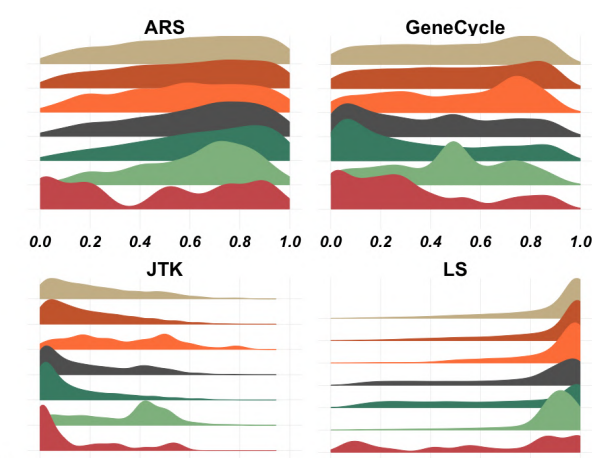

产
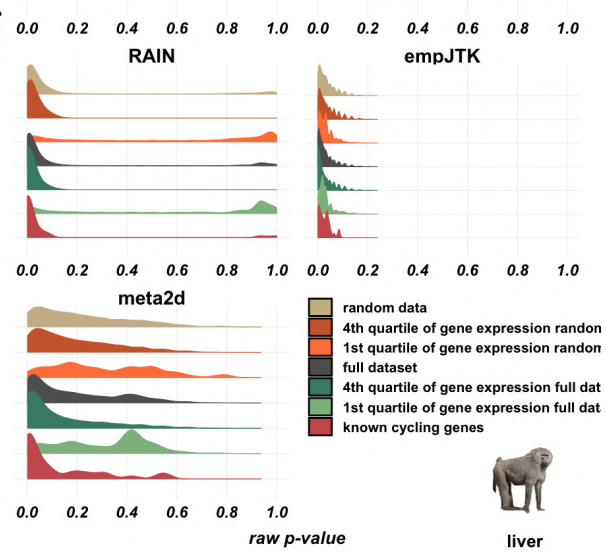

Fig. 546 


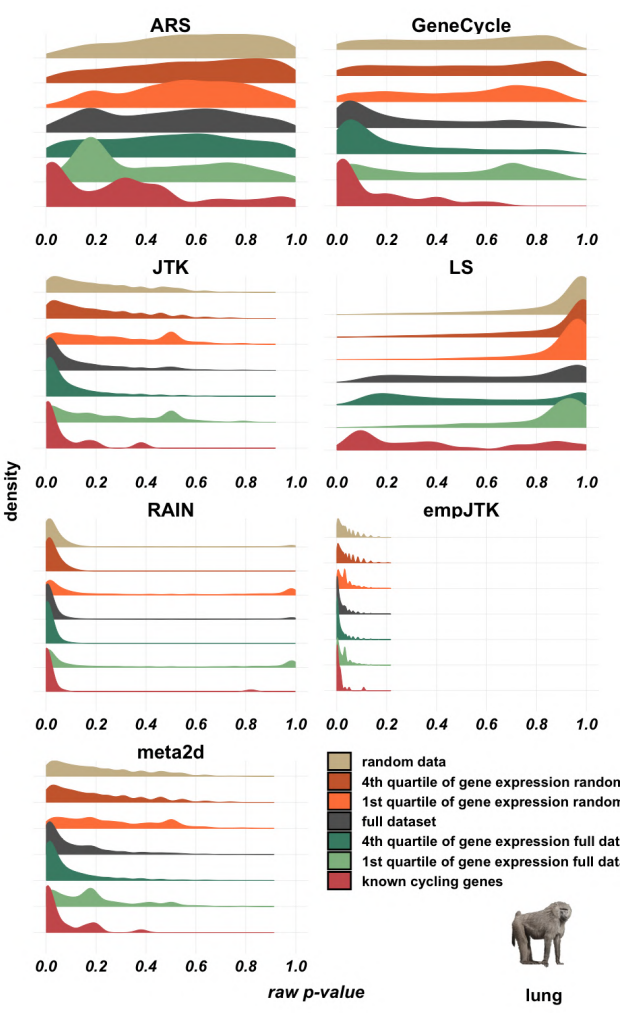

Fig. 547

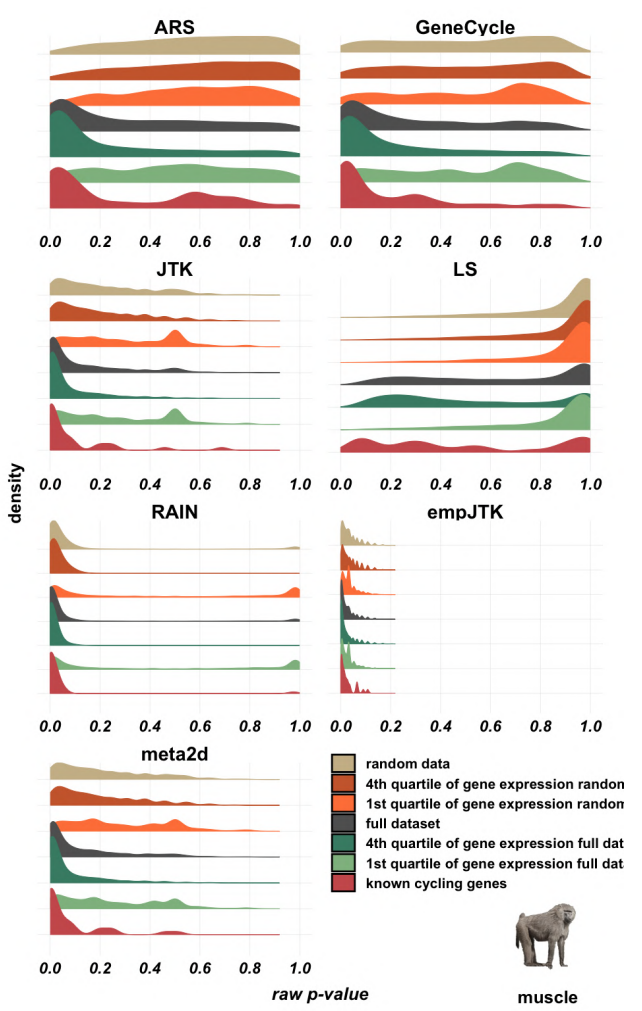

Fig. 548 


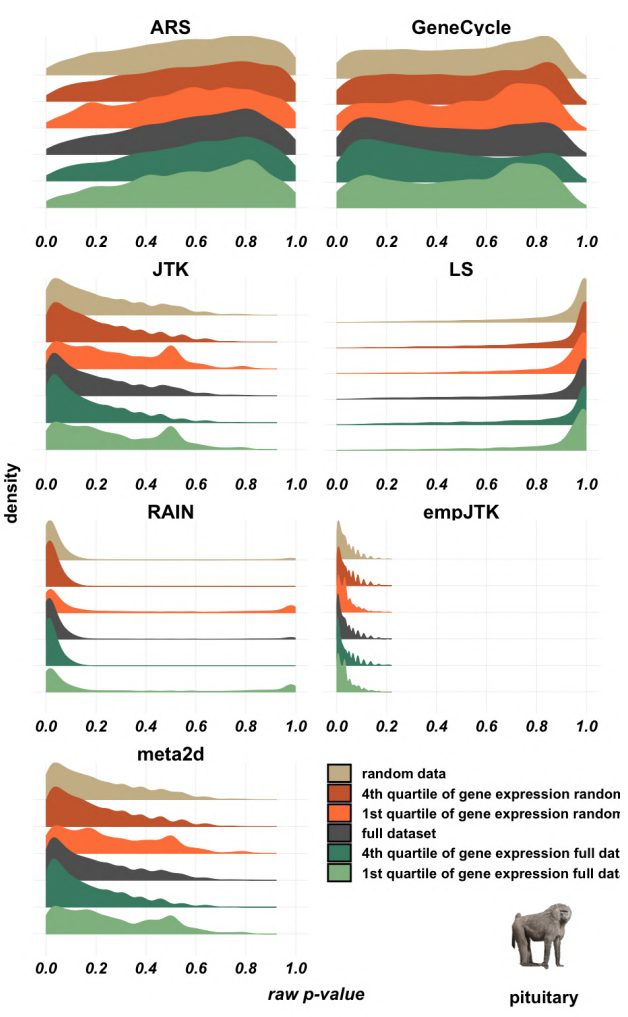

Fig. 549

Fig. $\mathbf{S 5 0}$

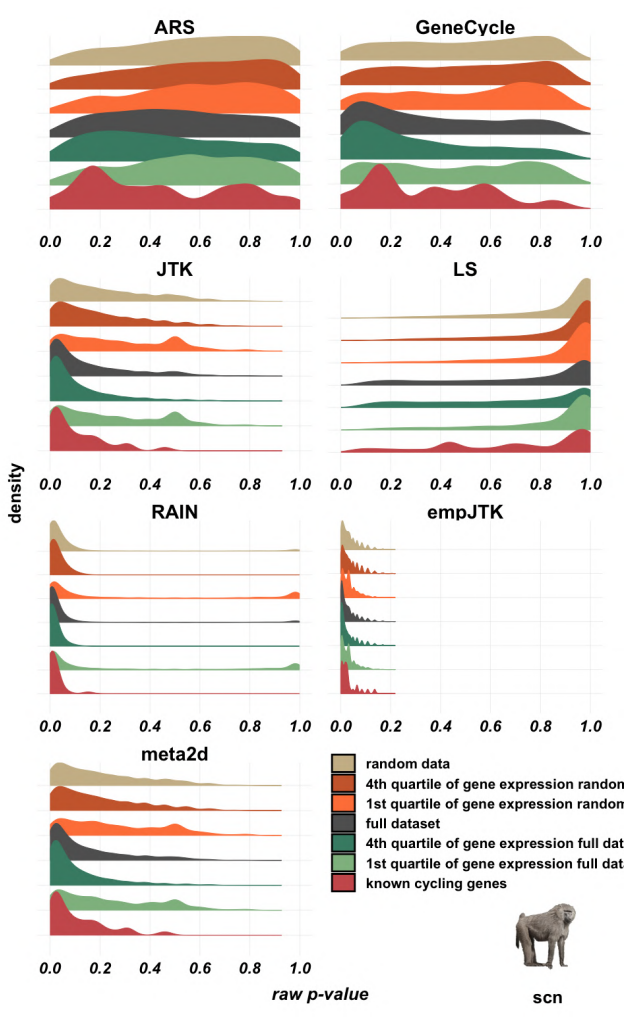




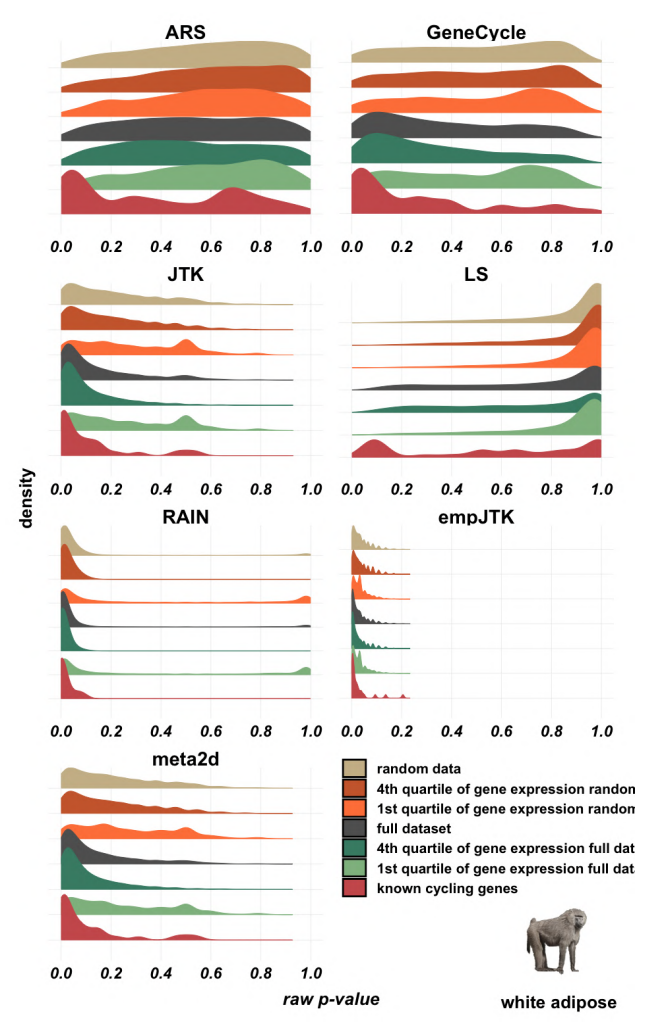

Fig. S51

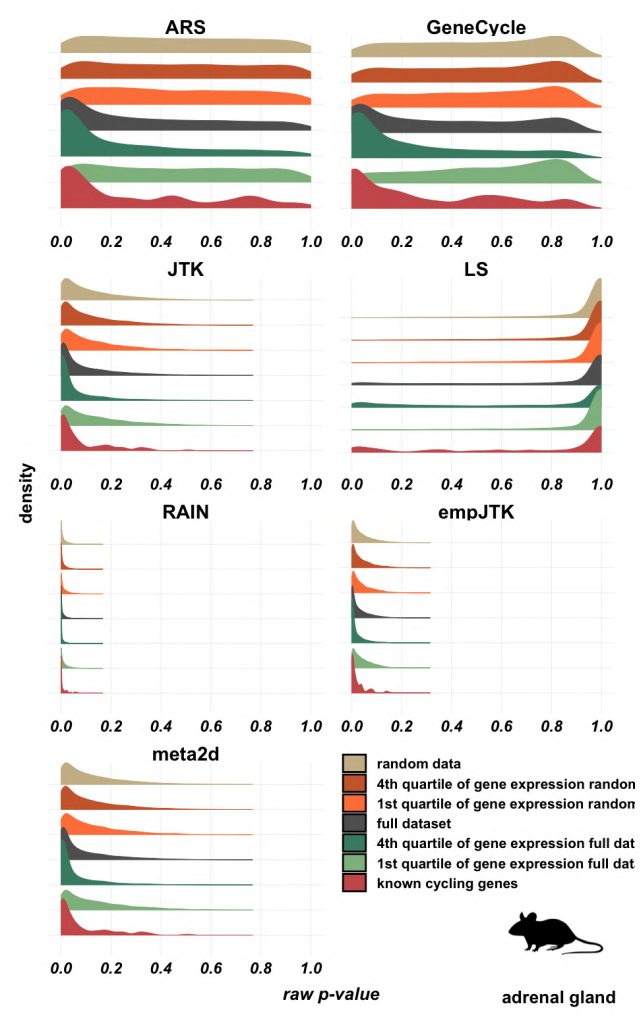

Fig. S52 


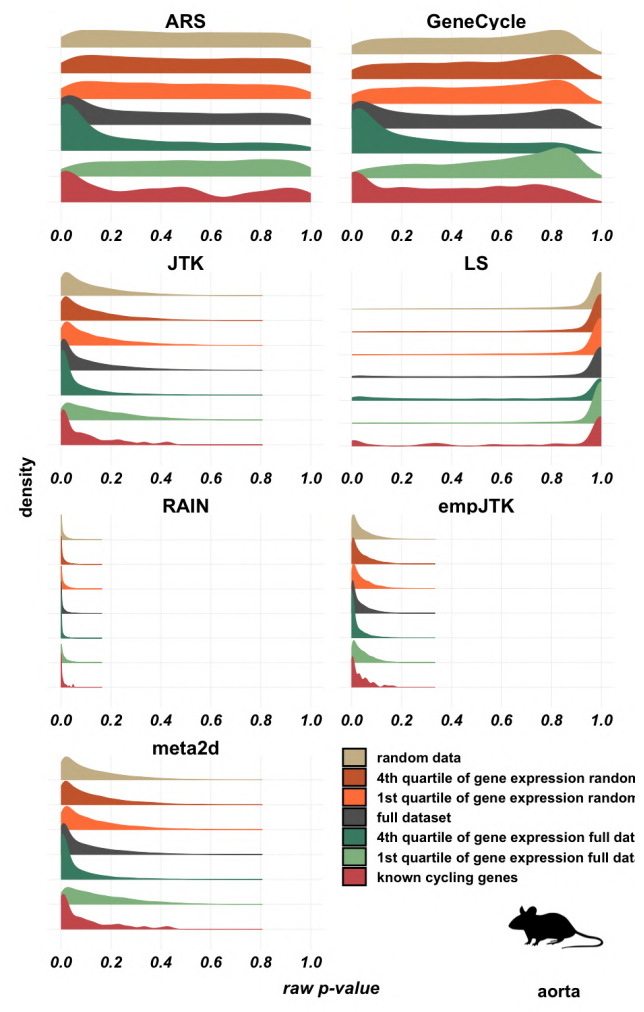

Fig. S53

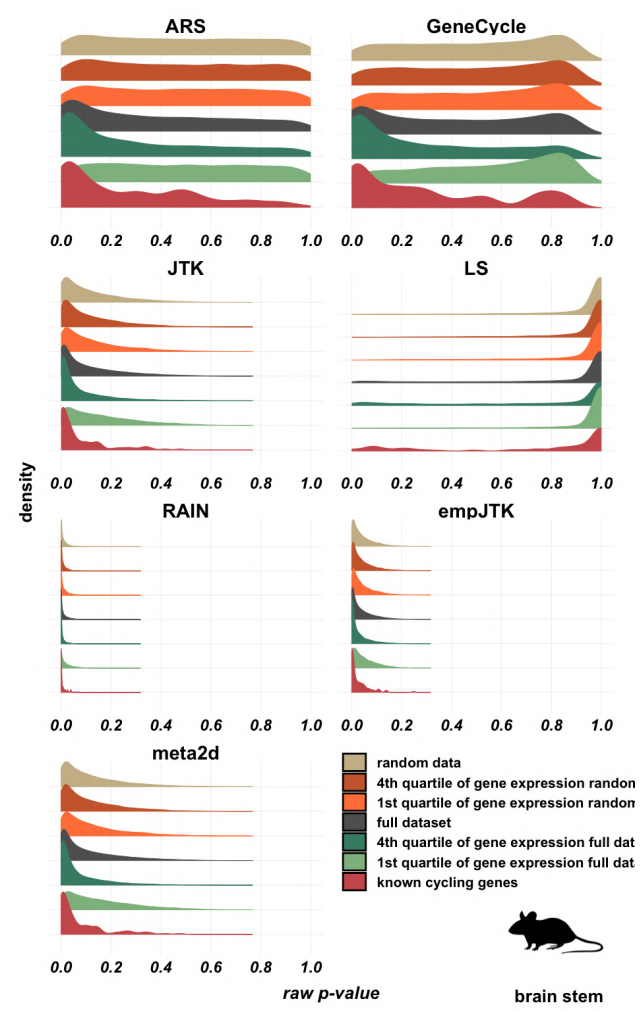

Fig. S54 


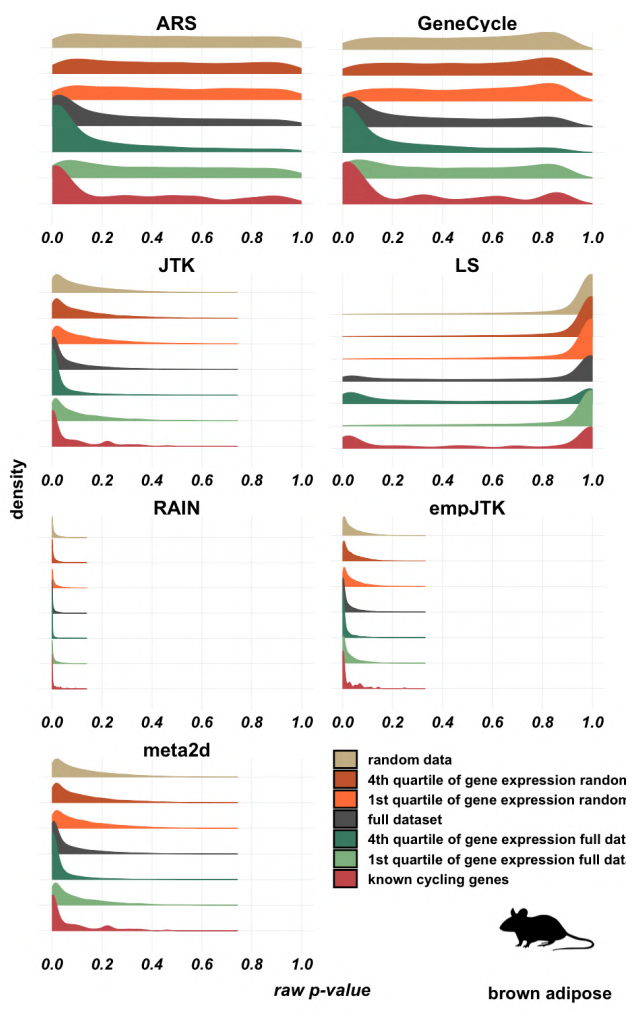

Fig. S55

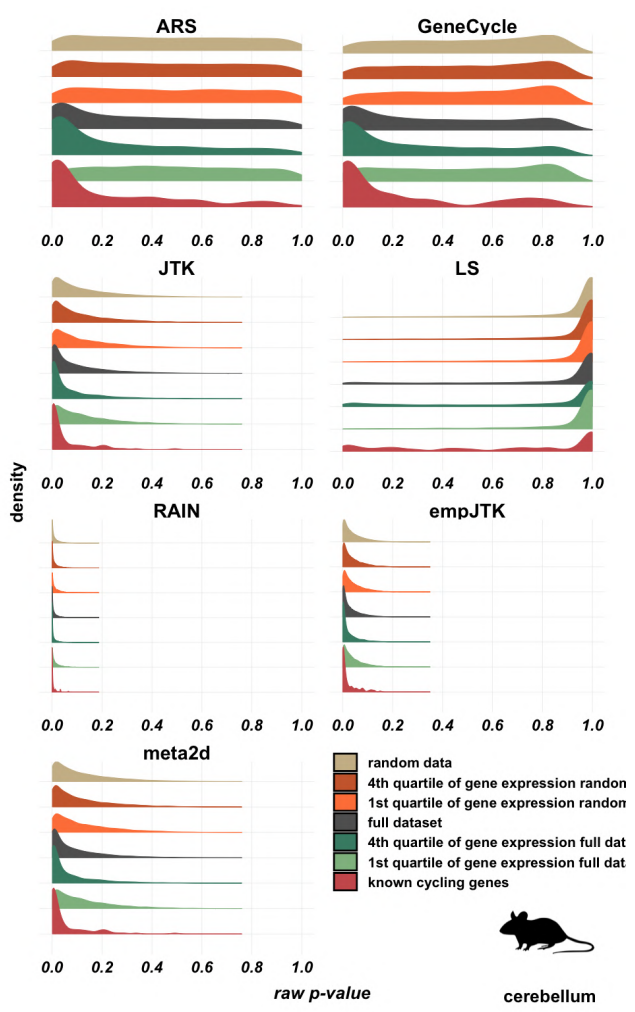

Fig. S56 


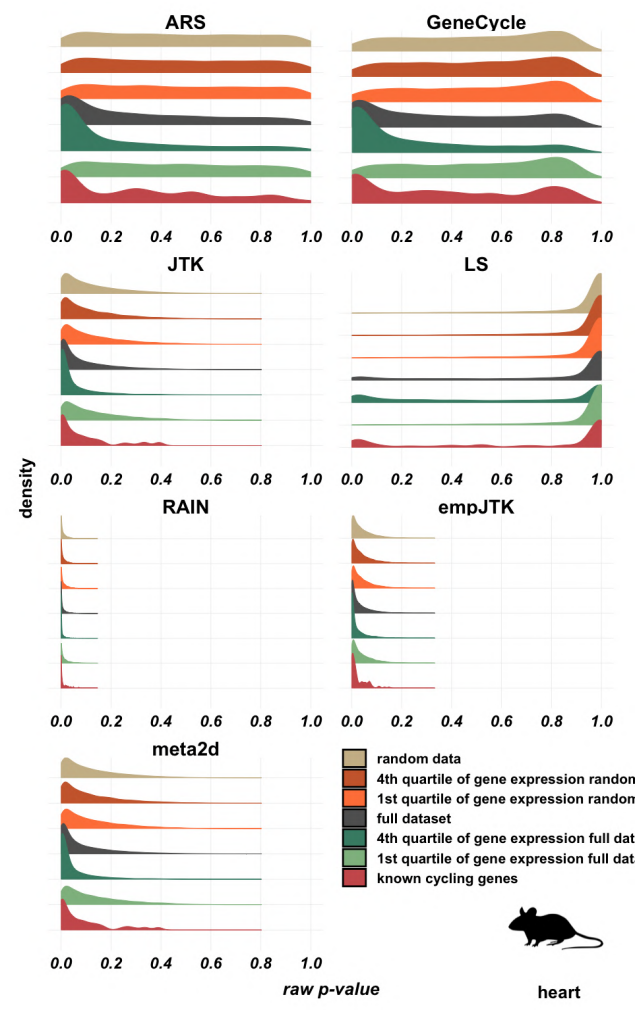

Fig. S57

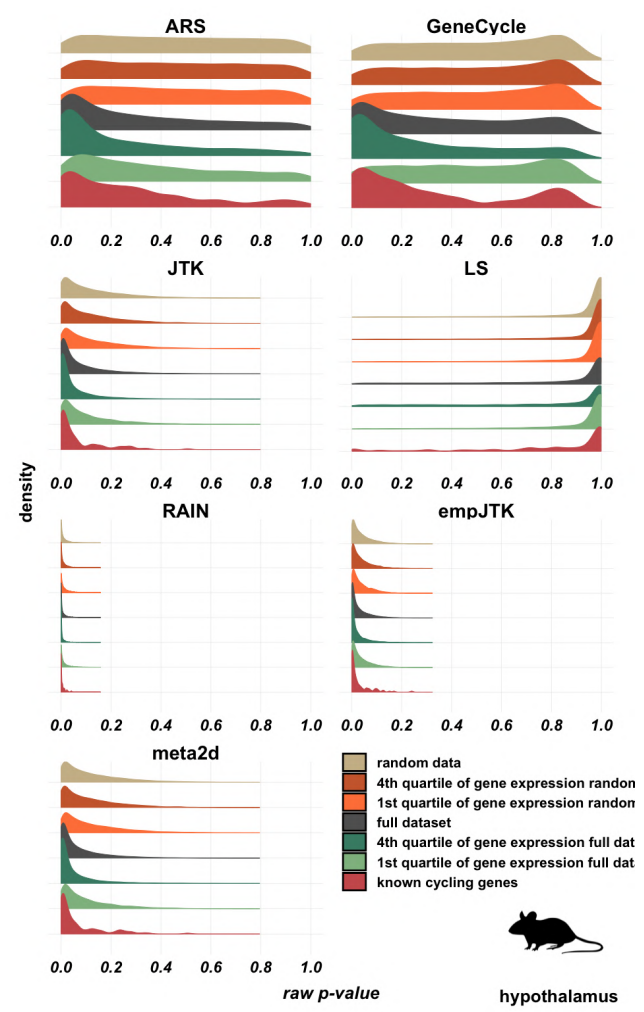

Fig. S58 


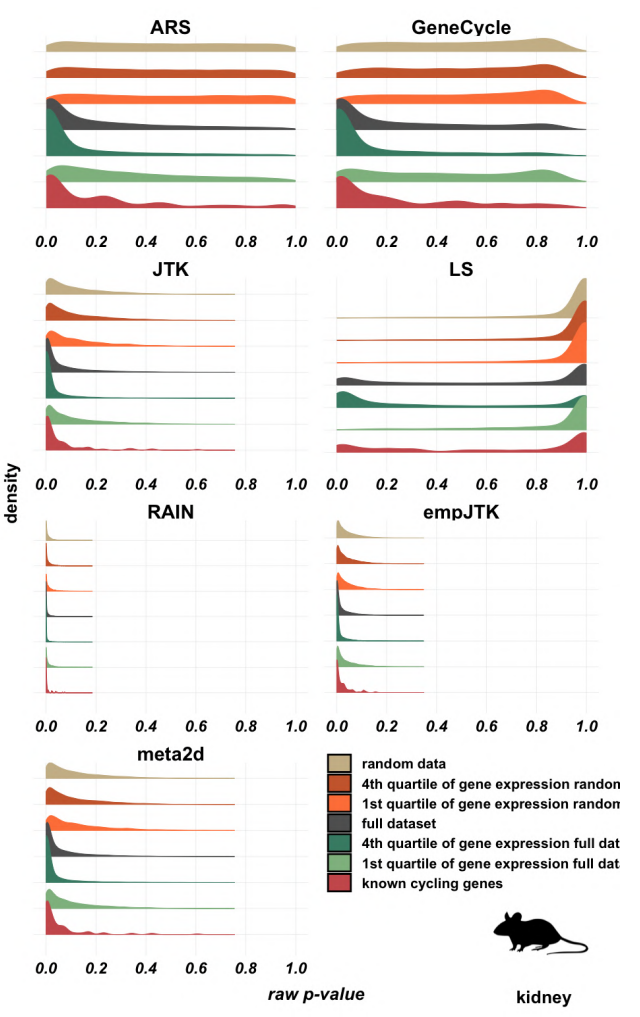

Fig. S59

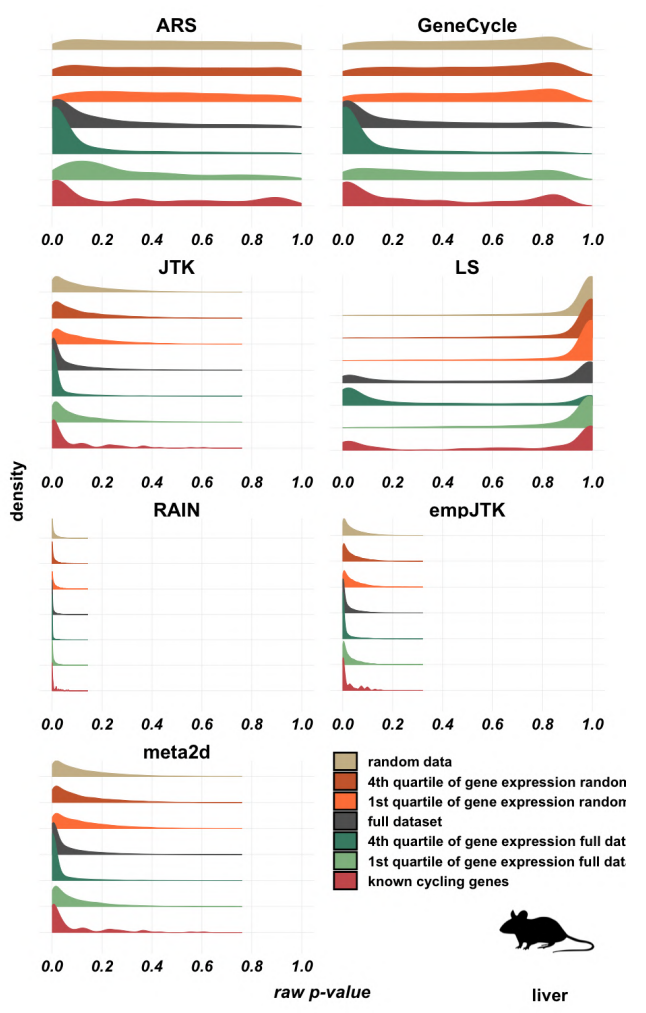

Fig. $\mathbf{S 6 0}$ 
Images credit: Anthony Caravaggi (mouse), Ian Quigley (zebrafish) both license CC BYNC-SA 3.0, Wikipedia GNU GPL Muhammad Mahdi Karim (baboon), and Public Domain for other images (from http://phylopic.org/) 